OPEN ACCESS

Edited by:

Stuart Keith Calderwood,

Beth Israel Deaconess Medical Center and Harvard Medical School,

USA

Reviewed by:

Dan Frenkel,

Tel Aviv University, Israel Daniel Olive,

INSERM UMR 891 Institut Paol

Calmettes, France

*Correspondence:

Daming Zuo

zdaming@smu.edu.cn;

Xiang-Yang Wang

xiang-yang.wang@vcuhealth.org

Specialty section:

This article was submitted to Immunotherapies and Vaccines,

a section of the journal

Frontiers in Immunology

Received: 07 December 2015

Accepted: 15 February 2016

Published: 01 March 2016

Citation:

Zuo D, Subjeck J and Wang $X-Y$ (2016) Unfolding the Role of Large Heat Shock Proteins: New Insights

and Therapeutic Implications.

Front. Immunol. 7:75.

doi: 10.3389/fimmu.2016.00075

\section{Unfolding the Role of Large Heat Shock Proteins: New Insights and Therapeutic Implications}

\author{
Daming Zuo ${ }^{1,2,3 *}$, John Subjeck ${ }^{4}$ and Xiang-Yang Wang ${ }^{5,6,7 *}$ \\ ${ }^{1}$ Department of Immunology, Southern Medical University, Guangzhou, China, ${ }^{2}$ State Key Laboratory of Organ Failure \\ Research, Department of Infectious Diseases, Nanfang Hospital, Southern Medical University, Guangzhou, China, \\ ${ }^{3}$ Guangdong Provincial Key Laboratory of Viral Hepatitis Research, Department of Infectious Diseases, Nanfang Hospital, \\ Southern Medical University, Guangzhou, China, ${ }^{4}$ Department of Cellular Stress Biology, Roswell Park Cancer Institute, \\ Buffalo, NY, USA, ${ }^{5}$ Department of Human and Molecular Genetics, Virginia Commonwealth University, Richmond, VA, USA, \\ ${ }^{6}$ VCU Massey Cancer Center, Virginia Commonwealth University, Richmond, VA, USA, ${ }^{7}$ VCU Institute of Molecular Medicine, \\ Virginia Commonwealth University, Richmond, VA, USA
}

Heat shock proteins (HSPs) of eukaryotes are evolutionarily conserved molecules present in all the major intracellular organelles. They mainly function as molecular chaperones and participate in maintenance of protein homeostasis in physiological state and under stressful conditions. Despite their relative abundance, the large HSPs, i.e., Hsp110 and glucose-regulated protein 170 (Grp170), have received less attention compared to other conventional HSPs. These proteins are distantly related to the Hsp70 and belong to Hsp70 superfamily. Increased sizes of Hsp110 and Grp170, due to the presence of a loop structure, result in their exceptional capability in binding to polypeptide substrates or non-protein ligands, such as pathogen-associated molecules. These interactions that occur in the extracellular environment during tissue injury or microbial infection may lead to amplification of an immune response engaging both innate and adaptive immune components. Here, we review the current advances in understanding these large HSPs as molecular chaperones in proteostasis control and immune modulation as well as their therapeutic implications in treatment of cancer and neurodegeneration. Given their unique immunoregulatory activities, we also discuss the emerging evidence of their potential involvement in inflammatory and immune-related diseases.

Keywords: heat shock protein 110, glucose-regulated protein 170, cytoprotection, innate immunity, antigen crosspresentation, inflammatory disease

\section{INTRODUCTION}

Heat shock proteins (HSPs) are constitutively expressed in all living organisms. The HSP nomenclature, originated from the observation of their induction by thermal stress, may also be used to describe other stress-inducible proteins, such as glucose-regulated proteins or GRPs (1-3). In contrast to cytoplasm-resident HSPs, GRPs mainly reside in the endoplasmic reticulum (ER). The mammalian HSPs are classified into several families of proteins based on their molecular size. Hsp110 and Grp170 are high molecular weight HSPs, which have been less studied compared to other conventional HSPs, e.g., Hsp70 and Hsp90 $(4,5)$. The transcription and subsequent protein expression of Hsp110 or Grp170 are stimulated by cytotoxic or proteotoxic stresses, such as heat 
shock, oxidative stress, chemical agents, hypoxia, viral infections, and inflammation. In such situations, these large HSPs work in concert with other chaperone molecules (e.g., Hsp70, Grp78) to restore protein folding and cellular function to counter proteotoxic stresses and promote cell survival (6-8). This intrinsic chaperoning feature of the large HSPs has significant implications in several diseases including neurodegeneration and cancer.

Given the superior protein-holding activity of these large HSPs and their unique ability to interact with the immune system, Hsp110 and Grp170 have been used to induce antigen/ tumor-reactive immune response for cancer eradication (5, 9, 10). These large HSPs can broadly chaperone antigens for presentation to $\mathrm{T}$ lymphocytes and amplify inflammatory signals in the extracellular environment, suggesting a potential endogenous immunostimulatory effects of these large HSPs during tissue stress or injury (e.g., microbial infection). Although the mechanism of their intracellular or extracellular action still needs to be elucidated, emerging evidence indicates that these large HSPs may be involved in regulation of an inflammatory response and bridging innate and adaptive immunity, which may contribute to the pathogenesis of inflammatory and immunerelated diseases. Here, we review the accumulating evidence of multifaceted functions of these large HSPs under physiological or pathological conditions and discuss the potential applications that exploit the distinct activity of the large HSPs to achieve therapeutic benefits.

\section{THE LARGE HSPS: DISTRIBUTION, INDUCTION, AND REGULATION}

Hsp110, also referred to as Hsp105, is one of the major eukaryotic HSPs and a member of conservative $\operatorname{Hsp} 70$ superfamily $(4,5)$. The studies of Hsp110 have been largely ignored until the cloning of its cDNA in the early 1990s (11-13). Hsp110 has been well characterized in mammals (i.e., human, mouse, and hamster) (11, 14-19). There appears to be two forms of Hsp110, 105 $\alpha$, and $105 \beta$ (43 fewer amino acids than $105 \alpha$ ) (14). Hsp $105 \alpha$ is expressed constitutively in the cytoplasm of cells and can be further induced by heat shock and other stressors, whereas Hsp $105 \beta$, an alternatively spliced form of Hsp $105 \alpha$ specifically localized in the nucleus, is strictly heat-inducible (20). However, the differential roles potentially played by these two versions of Hsp110 remain not well studied given their distinct compartmentalization. As one of the major HSPs, Hsp110 is easily detectable in most mammalian cell lines and tissues $(11,21)$. Hsp 110 is constitutively expressed in the various tissues, e.g., brain, liver, ovary, spleen, heart, lung, small intestine, and muscles, but most abundant in the brain $(13,14$, 22). Interestingly, mammalian cerebellum expresses little Hsp110 compared to other brain regions (13). It is not clear if the lack of Hsp110 expression contributes to the high sensitivity of the cerebellum to heat stroke or alcohol-associated toxicity $(23,24)$.

Hsp110 along with other HSPs could be induced in a specific set of stress conditions including hyperthermia, ethanol, oxidative reagents, recovery from anoxia (i.e., reperfusion injury), and inflammation $(25,26)$. Studies of heat shock factor (HSF) knockout mice indicated that the transcription factor HSF1 is required for induction of Hsp110, Hsp70, and Hsp25/27, by thermal stress (27). Exposure of $\mathrm{BALB} / \mathrm{c}$ mice to fever-range whole body hyperthermia $\left(39.5-40^{\circ} \mathrm{C}\right.$ for $\left.6 \mathrm{~h}\right)$ enhanced Hsp 110 expression in the lung, lymph nodes, and thymus (28). However, thermal stress did not appear to influence the Hsp110 levels in the rat nervous system $(29,30)$. Peptide mapping analysis and use of various deletion or substitution mutants revealed that Hsp110 is phosphorylated at Serine (509) in the $\beta$-sheet domain by casein kinase II (31). An early study reported that Hsp110 suppressed $70-\mathrm{kDa}$ heat-shock cognate protein (Hsc70)-mediated protein folding, while the phosphorylation of Hsp110 diminished its inhibitory activity in vitro (32). Intriguingly, phosphorylated Hsp110 is especially prominent in the brain compared to other tissues of mice or rats, suggesting that the phosphorylation of Hsp110 may be physiologically significant (33).

Like other HSPs reported to affect the morphologic development of cells and organisms (34), Hsp110 is also important for reproductive and embryonic development. Fujita and coworkers cloned two Hsp110 cognate cDNAs from testis, designated apg-1 and apg-2 (17, 35, 36). Apg-1 is developmentally expressed in human testicular germ cells and sperm, suggesting its potential role in spermatogenesis and fertilization $(17,35,37)$. Injection of antisense oligodeoxynucleotides targeting Hsp110 into the rat uterine horn on day 3 of pregnancy substantially reduced the number of the implanted embryos (38), implicating a physiological role for Hsp110 in regulation of reproduction. Indeed, Hsp110 displayed a differential expression pattern associated with the development of palate in mouse embryo (39). A recent study showed that Hsp110 plays an essential role in embryonic development of mouse hindlimbs (40). Strikingly, the integrity of Hsp110 in $\beta$-catenin degradation complex is required for Wnt signaling pathway, which can lead to embryonic defects upon abnormal activation $(41,42)$.

Grp170, also known as oxygen-regulated protein 150 (Orp150) or hypoxia-upregulated protein 1 (HYOU1), was first described as a $170 \mathrm{kDa}$ molecule inducible by glucose starvation (43). Hypoxia was soon found as a physiological inducer of Grp170 (44-48). Cloning and sequence analysis of Grp170 indicated that Grp170 represented a new stress protein family (12). Although they have a somewhat greater degree of sequence similarity to the Hsp110 family sequences than to members of the Hsp70 family, the Grp170s of mammals are essentially as diverged from the Hsp110 family of proteins as they are from the Hsp70s (4, 12, 49, 50).

Similar to other ER-resident GRPs (e.g., Grp78, Grp94/gp96), Grp170 possesses a C-terminal ER retention sequence, and therefore localizes in the ER after protein synthesis. Grp170 is inducible by glucose starvation, chronic anoxia/hypoxia, calcium depletion, low $\mathrm{pH}$, a variety of reducing conditions, stressinduced activation of the hypothalamic-pituitary-adrenal (HPA) axis, and viral infection that perturb the ER function $(44,51,52)$, suggesting that Grp170 participates in quality control of protein folding in the ER. Grp170 is co-regulated with Grp78 and Grp94/ gp96 by the unfolded protein response (UPR) (53). Transcription of these UPR-inducible genes is regulated by ER stress-response elements (ERSE) and key transcription factors such as the X-box DNA binding protein 1 (XBP-1) and ATF6 (54-57). In addition, 
Grp170 was also found to localize in the mitochondria and could be upregulated by $\mathrm{CHOP} / \mathrm{GADD} 153$ in response to mitochondrial and ER stress (58).

Although HSPs are generally considered to be intracellular proteins, they can be mobilized to the plasma membrane or released into the extracellular environment (59). HSPs do not seem to be secreted from cells via the classical pathway since they do not possess a signal peptide. Nonetheless, HSPs may be released from cells through either a passive (e.g., cell injury) or an active (translocation to the membrane for secretion) process. Hightower et al. first reported that rat embryo cells upon heatshock rapidly released Hsp70 and Hsp110 (60). The release of Hsp110 from human intestinal epithelial cells (IECs) was also observed in the physiological process of epithelial renewal, and this release was further increased upon pathological cell death (61). It was shown that Hsp110 preferentially associated with and stabilized misfolded protein in both the ER and cell periphery (62), suggesting Hsp110-based chaperoning activity may be involved in protein homeostasis at different locations. Recently, presence of Hsp110 on the plasma membrane of human B-cell non-Hodgkin lymphoma (B-NHL) cell lines was reported to correlate to the aggressiveness of lymphoma (63). Interestingly, Grp170 was identified on the surface of human sperm, implicating its potential physiological role in reproduction and fertilization (64). Additionally, Grp170 was found to be released from human cancer cells to the circulating system in patients with a range of neoplasms (65). Our study showed that both Hsp110 and Grp170 can gain access to the extracellular space upon cell necrosis and exhibit immunoregulatory activity (66). Although the biological significance of these surface or extracellular Hsp110 and Grp170 remain to be determined, these large HSPs are likely to exhibit multifaceted effects at cellular sites under physical and pathological conditions.

The constitutively expressed Hsc70, also known as HSPA8, and stress-inducible Hsp70 are central players in proteostasis control, including de novo folding, refolding of stress-denatured proteins, oligomeric assembly, protein trafficking, and proteolytic degradation (67). It has long been recognized that Hsp110 exists in multi-protein complexes containing Hsc70/Hsp70 (68-70) and Grp170 associates with other major GRPs (e.g., Grp78, Grp94/gp96) in the ER $(51,71)$, suggesting coordinated activities of chaperones in the maintenance of protein homeostasis. Our studies demonstrate that Hsp110 and Grp170 are highly effective in inhibiting the aggregation of heat-denatured protein substrates $(50,68,72-74)$. The genetic evidence also came from the observation that the Hsp110 deficiency impaired the refolding of heatdenatured luciferase in mammalian cells (75). Not surprisingly, Hsp110, Hsp70, and Hsp40 constitute a disaggregase machinery with capacity to efficiently disaggregate and refold aggregates of chemically or thermally denatured protein $(76,77)$, further highlighting a role of large HSP in molecular chaperoning and protein homeostasis. Hsp110 (78-81) and Grp170 (82-84) were recently proposed to serve as a nucleotide exchange factor (NEF) for Hsc70/Hsp70 and Grp78, respectively, during ATP hydrolysis of chaperoning cycle. Given the high efficiency of Hsp110 or Grp170 in protein holding, and their differential binding preferences for peptide residues compared to Hsc70/Hsp70 (85), we believe that
Hsp110 or Grp170 do not function solely as a co-chaperone or a NEF in cellular functions.

\section{LARGE HSP-MEDIATED CYTOPROTECTION AND TISSUE HOMEOSTASIS}

The intrinsic chaperoning property of large HSPs primarily contributes to their cytoprotective functions under stress conditions. Other mechanisms underlying their pro-survival activity may involve HSP-mediated suppression of the intracellular apoptotic pathways (86). We have demonstrated that both Hsp110 and Grp170 are significantly more efficient than Hsc70/Hsp70 in stabilizing and preventing irreversible aggregation of heat-damaged protein $(50,68,72-74)$, which may be attributed to the large size of these two chaperones due to the substantial expansion of their C-terminuses $(4,5)$. The overexpression of Hsp110 in Rat-1 and HeLa cells conferred partial thermotolerance and promoted cell survival to a severe heat shock (68). Eroglu et al. recently reported that Hsp110-deficient mice exhibit more serious brain damage and edema in controlled cortical impact model for traumatic brain injury (TBI) compared to wild-type counterparts (22). Enhancing the expression of the Hsp110 by celastrol treatment effectively reduced injury at the impact site (22), suggesting a potential benefit of using drugs to induce Hsp110 for reducing the pathological effects of TBI. Similarly, Grp170 was highly upregulated in astrocytes undergoing hypoxic stress (47), suggesting a cellular protective role of Grp170. Grp170 overexpression in cultured neurons increased their resistance to hypoxic/ischemia stress, whereas astrocytes with reduced Grp170 expression became vulnerable (87). Upregulation of Grp170 also effectively ameliorated hepatic ER stress and hypercholesterolemia-related liver damage (88).

The accumulation of misfolded or aggregated protein that is non-functional and cytotoxic has been implicated in the pathogenesis of neurodegenerative diseases (89). While it has been well established that conventional HSPs (e.g., Hsp70 or Hsp90) suppress the neurotoxicity associated with protein misfolding both in vitro and in vivo, emerging evidence indicates an essential neuroprotective effect of large HSPs. Mutant human $\mathrm{Cu} / \mathrm{Zn}$ superoxide dismutase 1 (SOD1) is associated with motor neuron toxicity and cell death in an inherited form of amyotrophic lateral sclerosis (ALS; Lou Gehrig disease). Song et al. showed that Hsp110 could prevent the aggregation of misfolded SOD1 species, resulting in abrogation of the neuron toxicity by rescuing the transport defect in transgenic mice and in axoplasm isolated from squid giant axons (90). A growing body of evidence suggests that soluble alpha-amyloid precursor protein (sAPPalpha), a cleavage product of APP, has neurotrophic and neuroprotective properties in Alzheimer disease (91). A recent study reported that Grp170 induced by sAPPalpha is part of this neuroprotective response (92). Erogu et al. provided first in vivo genetic evidence supporting the role of Hsp110 in pathogenesis of Alzheimer's disease (93). It was shown that Hsp110-deficient mice exhibited accumulation of hyperphosphorylated-tau and neurodegeneration. Crossing Hsp110-deficient mice with animal strain overexpressing mutant 
APP resulted in selective appearance of insoluble amyloid $\beta 42$. Analysis of brain tissues from patients with Alzheimer's disease showed the expression of Hsp110 in close proximity to $A \beta$ plaques. Together, these results underscore an essential role for Hsp110 in maintaining the proper folding environment that is required for phosphorylation/dephosphorylation of tau and APP processing in vivo.

High expression of HSPs that has been well documented in a wide range of human cancer cells supports their crucial role in proliferation and survival of tumor cells. Moreover, the levels of HSPs have been proposed to be useful prognostic biomarkers for tumorigenesis in some cancers (94, 95). Hsp110 is one of the most highly upregulated proteins in a variety of human cancers (96) and can suppress cancer cell apoptosis by preventing the release of cytochrome $c$ from the mitochondria (97-99). The small interfering RNA-mediated downregulation of Hsp110-sensitized human cancer cells to apoptotic induction (99). Yu et al. recently provided new insight into the molecular mechanism of Hsp110 overexpression in tumorigenesis (41). Hsp110 expression was correlated to upregulation of $\beta$-catenin and transcription of Wnt target genes in many cancers, including colorectal cancer and breast cancer. Knockdown of Hsp110 disrupted the integration of PP2A into the $\beta$-catenin degradation complex, resulting in degradation of $\beta$-catenin and inhibition of proliferation of colon cancer cell lines that harbor adenomatous polyposis coli (APC) mutation (41). Given that the majority of colon cancer patients have APC mutations and active Wnt/ $\beta$-catenin signaling, these findings establish Hsp110 as a prognostic biomarker and as a potential therapeutic target for the treatment of colon cancer $(100,101)$.

\section{LARGE HSPS IN INNATE IMMUNITY}

Several reports have documented the effect of endotoxin free large HSPs (i.e., Hsp110 and Grp170) in inducing co-stimulatory signals and cytokine responses in innate immune cells, such as dendritic cells (DCs) $(102,103)$. Tumor cells engineered to produce a secretable form of Grp170-stimulated DCs to produce the pro-inflammatory cytokine TNF- $\alpha$, which supports the extracellular Grp170 as a potential immunostimulatory "danger" molecule (104). Additionally, Hsp110 also induced mouse mammary carcinoma cells to elevate expression of IL-6, IL-12, and CD40 (102). A similar observation was made in mouse B16F10 melanoma cells treated with Grp170 (104).

The release of Hsp110 in subsets of human IECs into the intestinal lumen occurred as a consequence of epithelial renewal (61). The elevated levels of Hsp110 serve as an immunological "trigger," resulting in expression of CD1d and subsequent activation of natural killer T (NKT) lymphocytes (61). We recently demonstrated that extracellular Grp170 can function as a chaperone for microbial DNA, CpG oligodeoxynucleotides (CpG-ODN), which facilities immune-mediated recognition and clearance of pathogens (66). Grp170 was highly efficient in binding CpG-ODN and potentiated the endocytosis of CpG-ODN by macrophages, which led to the enhanced activation of toll-like receptor 9 (TLR9) (66). It should also be noted that Grp170 is able to directly interact with
TLR9 and this interaction increases during stimulation of TLR9 signaling. Furthermore, Grp170-CpG-ODN complex initiated innate immunity enhanced the protection of mice from challenge with Listeria monocytogenes compared to CpG-ODN alone (66). This finding uncovered a new feature of extracellular large HSPs in modulating the immune sensing of pathogen-associated molecular patterns (PAMPs). Together, the active cooperation between the extracellular chaperone and TLR9 may be essential for amplification of innate immunity and maintenance of the host homeostasis.

Exposure of mononuclear phagocytes or macrophages to hypoxia-induced upregulation of Grp170 expression, which was restricted to foam cells within atherosclerotic lesions (105). The biological function of Grp170 in macrophages may be linked to the survival or function of this inflammatory cell population that is known to contribute to the pathogenesis of atherosclerosis (106). Additionally, the expression of Grp170 was highly increased in alveolar macrophages and lung epithelial cells in mice upon lipopolysaccharide (LPS) challenge (107). Overexpression of the Grp170 was able to confer resistance to LPS-induced acute lung injury (107). However, the possible role of intracellular Grp170 in LPS-induced inflammatory response has not been examined. Recently, Giffin et al. reported that Grp170 was associated with viral interleukin-6 (vIL-6), a cytokine homolog encoded by human herpes virus 8 (52). This interaction increased the ability of vIL- 6 to bind gp130, thereby potentiating vIL-6-induced JAK/ STAT signaling, survival as well as migration of endothelial cells (52). This suggests that Grp170 can modulate vIL-6 function and promote pro-inflammatory signaling, angiogenesis, and cell proliferation.

\section{LARGE HSPS IN ANTIGEN CROSS-PRESENTATION}

In light of exceptional protein-holding capacity and superior immunostimulatory activity of the large HSPs (Hsp110, Grp170), we have created recombinant heat shock vaccines by complexing clinically relevant tumor protein antigens to these large chaperones $(74,108-112)$. These reconstituted complexes exhibited potent antitumor activities by eliciting antigen-specific cytotoxic lymphocytes (CTL) responses prophylactically and therapeutically. Due to the nature of these soluble antigen-targeted protein vaccines, it is believed that antigens-chaperoned by large HSPs are introduced into an antigen cross-presenting pathway in professional antigen-presenting cells (APCs), e.g., DCs $(9,113$, 114). Intracellularly processed antigenic peptides are then loaded onto major histocompatibility complex (MHC) class I molecules, followed by presentation to $\mathrm{CD}^{+} \mathrm{T}$ lymphocytes.

Despite the fact that these large HSPs efficiently facilitate a $\mathrm{CD}^{+} \mathrm{T}$ cell response to associated antigens, the mechanism underlying large HSP-enhanced antigen cross-presentation during interaction with DCs is not completely understood. The prolonged existence or stability of antigens is an important prerequisite for cross-presentation after internalization because antigen degradation by endo/lysosomal proteases can rapidly destroy putative antigenic epitopes (115). Hsp110 and Grp170 
are significantly more efficient than other chaperones in stabilizing heat-denatured protein substrates $(50,72)$, which may help to protect antigenic epitopes from being degraded. In addition, these large HSPs may be able to influence intracellular trafficking of antigens to promote cross-presentation. Kutomi et al. showed that Grp170 shuttled the chaperoned peptide into the Rab5 ${ }^{+} E E A 1^{+}$static early endosomes and transferred the peptide onto the recycling MHC class I molecules (116).

Using a clinically relevant melanoma protein antigen (i.e., gp100), we recently investigated the trafficking pathway of Grp170-gp100 vaccine complex internalized (117). We showed that the Grp170 directed the antigen gp100 efficiently to the ER following uptake into DCs. Grp170-facilitated antigen processing and presentation was dependent on the endoplasmic reticulumassociated protein degradation (ERAD) pathway involving Sec61, which targets gp100 for proteasome-mediated degradation in the cytosol and subsequent integration into the conventional MHC class I restricted antigen-processing pathway. Grp170 can assist protein antigen to escape from lysosomal degradation and shuttle the antigen into the ER from the early endosomal compartment, possibly via a previously reported "ER-endosome fusion" process (118-120). Internalized Grp170 may be directly involved in the ERAD, because Grp170 in the complex enhanced the interaction of gp100 with several molecules known to participate in this pathway (e.g., Sec61 $\alpha$, VCP/97, CHIP, Grp78). It is conceivable that partially unfolded gp100 protein during the vaccine preparation serves as an ERAD target once accessing the ER. Since endogenous Grp170 also binds to Sec61 $\alpha$, it is possible that internalized Grp170 collaborates with other ER chaperones to guide antigen retrotranslocation. Interestingly, cytoplasmic chaperone Hsp110 was recently shown to regulate folding as well as quality control of cystic fibrosis transmembrane conductance regulator (CFTR) in the ER (62). It is of interest to determine whether endogenous Hsp110 is also involved in Grp170-enhanced antigen crosspresentation by DCs.

It has been established that antigen cross-presentation promoted by HSPs, including Hsp110 and Grp170, requires uptake of the HSP-antigen complexes by pattern recognition scavenger receptors (SR), such as CD91, LOX1, scavenger receptor A (SRA), and SREC (121-127). Although SRA serves as a binding structure on DCs for exogenous Hsp110 or Grp170, the loss of SRA does not seem to significantly alter the overall capacity of DCs to process and present Hsp110-associated antigen (i.e., gp100) $(108,127,128)$. On the contrary, the lack of SRA increased the ability of DCs pulsed with large HSP-gp100 complex to stimulate gp100-specific naive T cells (108). Given that LOX-1 and SREC have been shown to potentiate Hsp70-mediated antigen crosspresentation $(121,125)$, we postulate that SRs are functionally distinct upon interactions with HSPs that carry antigens (129).

\section{USE OF LARGE HSPS FOR DEVELOPMENT OF CANCER VACCINES}

Numerous studies have documented the immunogenicity of tumor-derived HSPs, which has been attributed to the individually distinct array of antigenic peptides associated with these chaperone proteins (130-138). Our early study showed that vaccination of mice with Hsp110 or Grp170 purified from methylcholanthrene-induced fibrosarcoma resulted in a complete regression of the tumor (139). Moreover, tumor-derived Hsp110 or Grp170 appeared to elicit a more potent antitumor response on a molar basis than Hsp70 (139), which may be explained by their superior antigen chaperoning capability. Several reports suggest that the affinity with which the chaperone binds antigen determines its ability to induce a CTL response (140-142). Using a more aggressive and less immunogenic mouse B16 melanoma model, we demonstrated that tumor-derived Grp170 preparations delayed tumor progression and reduced pulmonary metastases (143).

HSP-peptide complexes derived from patient tumors represent an autologous or personalized vaccine. However, the yield of such a vaccine in the clinic is low for certain types of cancer due to requirement for patient specimen (144). To overcome this limitation, we developed a recombinant chaperone vaccine by reconstituting Hsp110/Grp170-tumor protein antigen complexes under heat shock conditions $(72,110,112,145)$. A "natural chaperone complex" between Hsp110 and the intracellular domain (ICD) of human epidermal growth factor receptor 2 protein (HER-2)/neu elicited both $\mathrm{CD}^{+}$and $\mathrm{CD} 4^{+} \mathrm{T}$-cell responses against ICD. The Hsp110-ICD complex also significantly enhanced ICD-specific antibody responses relative to that seen with ICD alone (112). Subsequent studies showed that the Hsp110-ICD complex was able to inhibit the development of spontaneous mammary tumors in FVB-neu (FVBN202) transgenic mice (145). Consistent with this finding, immunization with melanoma antigen gp100 complexed with Hsp110 exhibited therapeutic efficacy against established B16 melanoma (72). Strikingly, Hsp110 was more effective than complete Freud's adjuvant in inducing an antitumor immune response (72), which is likely to be due to the unique capability of the large HSPs in promoting antigen cross-presentation. The extensive preclinical studies by us and others have validated this recombinant chaperone vaccine approach that uses large HSPs to target tumor antigens to professional APCs (74, 108-111, 146-148), which provide strong scientific rationale for exploiting these large HSPs to develop synthetic and non-toxic vaccines for cancer immunotherapy.

The similar principle has been used to prepare a recombinant vaccine to induce an immune response to infection. McLaughlin et al. showed that recombinant Hsp110 can efficiently bind to complete viral antigens and enhance monocyte-stimulated proliferation of recall $\mathrm{CD} 4{ }^{+} \mathrm{T}$ cells in vitro. However, the complexes failed to improve primary immune response in vivo (149). Therefore, more studies are necessary to understand immunoregulatory activity of the large HSPs in vaccine design directed against infectious diseases.

Using colon-26 (CT26) cancer cells stably transfected with Hsp110, we showed that Hsp110 overexpression markedly enhanced the immunogenicity of the tumor in vivo. Immunization of mice with irradiated CT26-Hsp110 cells caused growth inhibition of unmodified CT26 tumor, associated with increased frequency of tumor-specific T cells (150). Similarly, engineering of TRAMP-C2 mouse prostate cancer cells to secrete Grp170 profoundly enhanced tumor immunogenicity, indicated 
by increased levels of tumor-infiltrating $\mathrm{CD}^{+} \mathrm{T}$ cells, enhanced cytolytic activity, and improved control of distant tumors (104), suggesting that the induction or manipulation of large HSPs for secretion may help break immune tolerance to cancer cells. We also found that the secreted Grp170 chaperoned full length tumor protein antigens, which can be potentially captured by DCs in the tumor microenvironment (151). Considering abundant tumor antigens present in cancer cells, we investigated the feasibility of intratumoral delivery of Grp170 using an adenovirus to promote antitumor immunity. We showed that the adenovirus encoding a secretable form of Grp170 elicited a tumor-reactive CTL response (152). Furthermore, this Grp170-expressing adenovirus combined with an adenovirus encoding melanoma differentiation-associated gene-7/interleukin-24 ( $m$ da-7/IL-24), a cancer-specific, apoptosis-inducing gene (153), led to a synergistic systemic antitumor effect as shown by improved control of both treated and untreated prostate cancers (152).

The significance of pathogen-sensing TLR signaling in enhancing antigen presentation by specialized APCs (e.g., DCs) and in bridging innate and adaptive immune responses has been well established (154). Incorporating pathogen-associated molecules or TLR agonists into therapeutic vaccines can potentially augment immune activation. Recently, we engineered a chimeric chaperone by fusing Grp170 with a defined NF- $\mathrm{KB}$-activating domain of the TLR5 agonist flagellin. This chimeric molecule, termed Flagrp170, combined action of the large HSP in facilitating antigen cross-presentation and a microbial immunostimulatory signal for functional activation of DCs (155). Intratumoral administration of an adenovirus expressing Flagrp170 restored systemic antitumor immunity against B16 melanoma and distant lung metastases compared to either unmodified Grp170 or Flagellin. The therapeutic potency of Flagrp170 was also confirmed in mouse models of prostate cancer and colon cancer. The mechanistic studies showed that Flagrp170-provoked activation of tumor-reactive $\mathrm{T}$ cells required $\mathrm{CD} 11 \mathrm{c}^{+} \mathrm{DCs}$ and $\mathrm{CD} 8^{+} \mathrm{DCs}$. Although research is needed to better understand the molecular and cellular bases of immunoregulation by this chimeric chaperone in the immunosuppressive tumor environment, our results support the use of this new generation chaperone molecule for future design of optimized vaccines to achieve improved treatment outcomes. In a separate study, Chen et al. reported that Grp170-HPV16 E7 ${ }_{49-57}$ peptide complex plus the TLR3 agonist polyinosinic-polycytidylic acid or poly(I:C), a synthetic analog of double-stranded RNA and a molecular pattern associated with viral infection, induced synergistically an immune response to cervical cancer in mice (156). Therefore, strategic inclusion of a microbial component in large HSP-based vaccine regimen will further strengthen its immunostimulatory capacity in driving an effective CTL response for tumor eradication.

The levels of HSPs, including large HSPs, are generally elevated in various human tumors possibly due to the increased requirement for chaperone molecules to stabilize the mutated or oncoproteins in cancer cells $(41,157)$. A recent study established a direct correlation between Hsp110 expression and lymphoma aggressiveness (63). Treatment of human B-NHL cell lines with an antiHsp110 antibody had no direct effect on cell cycle or apoptosis, but significantly reduced the tumor burden in xenotransplanted immunodeficient mice (63). Hsp110 was reported as a prognostic biomarker for the poor survival of patients with breast cancer and melanoma (41). Similarly, both the protein and mRNA levels of Grp170 were significantly upregulated in several cancer cell lines compared to their normal counterparts (158). Induced overexpression of Grp170 inhibited the senescence and apoptosis of human breast cancer cells, not normal cells (158). Considering the potential involvement of these large HSPs in oncogenesis, Hsp110 or Grp170 itself may represent a novel tumor-associated antigen for immunotargeting. Indeed, vaccination with Hsp110 cDNA resulted in growth inhibition of colorectal CT26 and melanoma B16 tumors, which was associated with stimulation of both Hsp110-specific CD4 ${ }^{+}$and $\mathrm{CD} 8^{+} \mathrm{T}$ cells (159). Although our recombinant chaperone vaccine does not appear to induce a significant cellular or humoral response to the Hsp110 (112), such a response may be ideal for those cancers with high expression of the large HSPs.

\section{LARGE HSPS AND INFLAMMATORY DISEASES}

Inflammatory disease is a term that collectively describes a group of apparently unrelated conditions that have common inflammatory pathways leading to inflammation, which may result in various organ damages $(160,161)$. Although each of these diseases has distinctive epidemiology and pathophysiology, the dysregulated inflammatory response is believed to be pivotal to the disease pathogenesis. In addition to conventional inflammatory disorders, such as inflammatory bowel disease (IBD), diabetes, rheumatoid arthritis (RA), and multiple sclerosis (MS), some other diseases, such as idiopathic pulmonary fibrosis (IPF), myocardial infarction (MI), were recently shown to involve inflammatory responses as well. Despite that HSPs have been implicated in inflammatory and immune-mediated diseases over the past few decades (162-166), the roles of the large HSPs in disease pathogenesis, especially in immune-related processes, remain less investigated. Understanding of molecular actions of Hsp110 and Grp170 in classical inflammatory diseases and those that involve an inflammatory process may provide new insights into disease mechanisms and lead to new strategies for prevention and therapy of these diseases.

An early study by Colgan et al. showed that Hsp110 released from IECs contributes to CD1d surface expression in a novel autocrine pathway, suggesting that Hsp110 regulation of CD1d represents the "physiologic inflammation" in mucosal tissue sites (61). Since CD1d presents self and microbial lipid antigens to NKT cells, it is possible that the Hsp110-CD1d axis might contribute to the pathogenesis of inflammatory diseases, e.g., IBD. Surprisingly, a recent study from this group reported that bone-marrow-derived CD1d signals induced NKT cell-mediated intestinal inflammation; however, engagement of epithelial CD1d elicits protective effects through the STAT3-dependent regulation of IL-10, Hsp110, and CD1d itself (167), which highlights a role of Hsp110 in IEC-dependent maintenance of gut homeostasis. In line with these observations, pharmacological stimulation of Hsp110 expression may be exploited to prevent 
colorectal inflammation and favorably affect the progression of IBD. Indeed, human HSP A4 (HspA4, also called Apg2), a member of the Hsp110 family, is inducible by chronic inflammation $(164,168)$. A recent study showed that increased HspA4 inhibited apoptosis of inflammatory cells, thereby augmenting immune response in the gut through the upregulation of Bcl-2 and IL-17 expression, which led to treatment resistance in IBD (164). This result also suggests that HspA4 may be used as a potential biomarker for refractory IBD. Interestingly, Zebrafish HspA4 was also upregulated in the intestinal epithelium within the gut under inflammatory stress conditions (169). Using HspA4-deficient mice and human tissue samples, Sakurai et al. showed that the expression of HspA4 was inversely correlated to gastric ulcer healing induced by endoscopic submucosal resection (170). Further studies revealed that HspA4 downregulated the expression of stromal cell-derived factor 1 (SDF-1, also known as CXCL12), which signals through its cognate receptor CXC chemokine receptor 4 (CXCR4). The resultant inhibition of cell migration delayed gastric ulcer healing (170).

Obesity and associated insulin resistance predispose individuals to develop chronic metabolic diseases, such as type 2 diabetes. Emerging evidence supports an important role for Grp170 in insulin release (171-173) or insulin resistance in diabetes (174, 175). Kobayashi et al. showed that Grp170 was highly expressed on pancreatic beta cells and decrease in serum glucose concentration by fasting strongly suppressed Grp170 expression in the pancreas concomitant with decreased insulin level in the serum (172). Interestingly, titer of autoantibodies against Grp170 was elevated during high-fat diet feeding (171). A significant increase in autoantibodies to Grp170 was also observed in patients with type I diabetes (176). However, the pathophysiological effect of these autoantibodies to Grp170 in diabetes remains unclear.

Involvement of Grp170 in improving insulin sensitivity of the skeletal muscle and liver was established in type 2 diabetes (175). Overexpression of Grp170 was shown to delay the onset of disease and improve insulin sensitivity, subsequently ameliorated glucose tolerance in diabetic animals. Conversely, reduction of Grp170 in the liver facilitated the disease progress and decreased insulin sensitivity (174). Mechanistic studies suggested that the improved insulin sensitivity by Grp170 was executed though attenuation of oxidative stress and augmentation of insulin signaling in the skeletal muscle and liver (174). Recently, Deng et al. showed that Grp170 expression on pancreatic beta cells decreased gradually during the pathogenesis of acute necrotizing pancreatitis (177). Dekki et al. reported that transthyretin (TTR), which promotes insulin release and protects against pancreatic beta cell death, was associated directly with Grp78, Grp94, and Grp170 in pancreatic beta cells (178). Treatment of beta cells with physiological concentrations of TTR triggered a pronounced increase in intracellular calcium concentration (179). The TTRinduced change in calcium levels was abolished when cells were treated with an antibody against Grp78 (178). Although Grp170 was not directly studied in this model, it is likely that Grp170 along with other chaperone molecules in these multimeric complexes collaboratively regulate the internalization or activity of TTR, thereby affecting insulin release. Several studies have shown that intracellular Grp170 was involved in regulation of calcium signaling or calcium homeostasis $(58,180,181)$. However, it remains to be determined if such a pathway alters the function of pancreatic beta cells and inflammatory processes associated with diabetes.

Idiopathic pulmonary fibrosis is a progressive chronic disease associated with inflammatory responses, fibrosis, and lung dysfunction. Treatment of mice with bleomycin-induced lung damage with concurrently enhanced expression of Grp170 in the lung (182). Despite a modest exacerbation of inflammatory responses in Grp $170^{+/-}$mice, these animals showed significantly ameliorated pulmonary fibrosis, alteration of respiratory dysfunction compared to wild-type counterparts. Although Grp170 appeared to be a protectant against bleomycin-induced lung injury, it promoted lung fibrosis by increasing levels of TGF- $\beta 1$ and myofibroblasts (182).

Myocardial infarction (i.e., heart attack) is the irreversible myocardial cell damage or death, which occurs during prolonged ischemia caused by blockage of a coronary artery. Grp170 overexpression significantly reduced the hypoxia/reoxygenationinduced cardiomyocyte death by inhibiting activation of capase- 3 and release of mitochondrial cytochrome $\mathrm{C}$. This protective effect of Grp170 also inhibited injury caused by myocardial ischemiareperfusion in vivo (181). In addition, increased levels of Grp170 and Grp170-derived peptide fragments was shown in the plasma of patients after MI, which was associated with enhanced ER or hypoxic stress and suggested to be prognostic marker that predicts a poor outcome (183). Accumulating evidence indicates that MI-triggered inflammatory response is involved in injury, repair, and remodeling of the infarcted heart $(184,185)$. Recent study showed that stimulation of inflammasomes induced the caspase activation associated with maturation and secretion of biologically active IL- $1 \beta$, which can cause additional loss of functional myocardium and heart failure in mouse model of MI (186). While intracellular Hsp90 has been reported to regulate activation of inflammasome (187), the potential effect of intracellular or extracellular Grp170 on inflammasome activity as well as in the pathophysiology of MI remain to be examined. Elucidating the inflammatory pathways and their contributions to the pathogenesis of MI may lead to novel therapies for preventing post-infarction heart failure.

Although large HSPs, like other chaperone molecules, function to primarily promote and restore cellular or tissue homeostasis, they may be involved in immune pathology through several mechanisms given their potential immunoregulatory effects (Figure 1). Of note, extracellular Grp170 secreted from intact cells or released from injured cells facilitate the delivery of Grp170-antigen complex to DCs via interaction with surface SRs, thereby enhancing the cross-presentation of the HSP-bound antigens for $\mathrm{T}$ cell activation $(9,113,114,117)$. In addition to functioning as "danger" molecules that alert the immune system of tissue damage $(102,103)$, the extracellular Grp170 has a capacity to amplify the inflammatory response triggered by microbial signal (66) and possibly endogenous damage-associated molecular patterns (DAMPs) as well. Indeed, host-derived DAMPs, such as RNA (188) and DNA $(189,190)$, can also be recognized by TLRs or other pattern recognition receptors that provokes sterile inflammation or inflammatory diseases (191-194). Compared 


\section{Proteotoxic stress, cell injury, microbial infection}
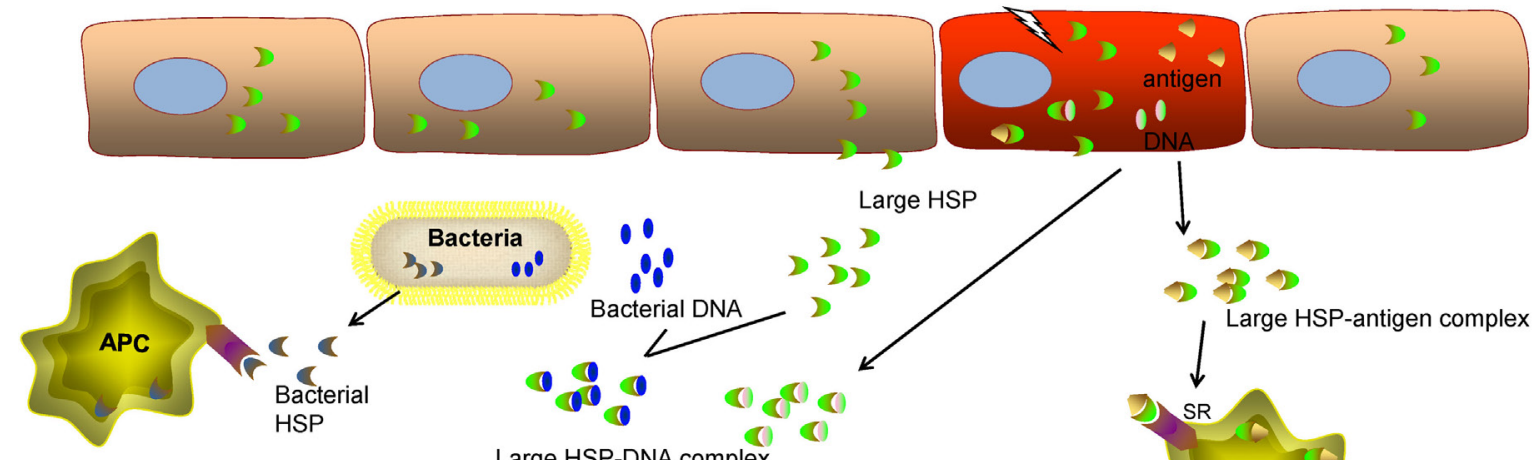

Large HSP recognition of large HSP
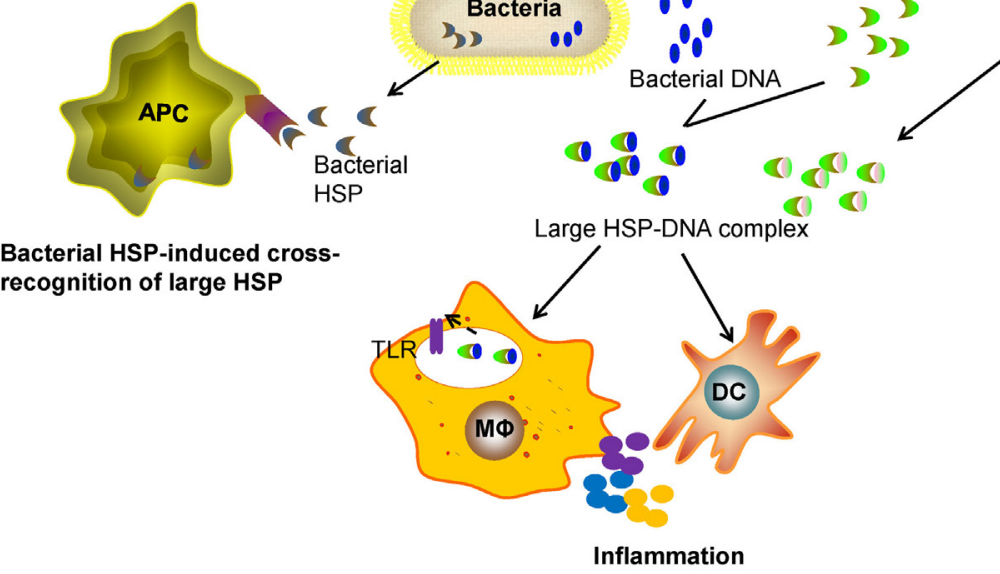

Activation of self-reactive $T$ cells Production of autoantibodies

FIGURE 1 | The potential role of large HSPs in inflammatory or immune-related diseases. Intracellular HSPs typically function as molecular chaperones to promote proteostasis, counteract cellular stresses, and improve cell survival. The extracellular large HSPs, released from the host cells, caused by proteotoxic stresses, cell injury, or microbial infection, may be involved in regulation of immune pathways that contribute to immune pathologies. The large HSPs complexed with self-antigens can be captured by professional antigen-presenting cells (APCs) through scavenger receptor (SR)-mediated endocytosis. Large HSP-based chaperoning enhances the cross-presentation of associated antigens and activation of self-reactive CD8 ${ }^{+} \mathrm{T}$ cells. The processing of these HSP-antigen complexes may result in activation of $\mathrm{CD} 4^{+} \mathrm{T}$ cells and production of autoantibodies by B lymphocytes. It is also likely that a cellular or humoral response directed to the large HSP itself can be induced in certain pathological conditions. The released large HSPs from injured cells, if complexed with self-DNAs or with microbial DNAs in the case of infection, can provoke and amplify inflammation or an innate immune response triggered by toll-like receptors (TLRs) present on sentinel cells, such as macrophages $(\mathrm{M} \varphi)$ or dendritic cells (DCs). Due to the conserved sequence, pathogen-derived microbial HSPs from (e.g., bacteria) may induce an immune response that cross-reacts with self HSPs during chronic infection.

with healthy individuals, serum from patients with autoimmune diseases, patients with trauma, and children with septic shock shows high concentrations of Hsp70 (59), even though Hsp110 or Grp170 was not examined in this study.

Cross-recognition of the self and the mycobacterial HSPs by $\mathrm{T}$ cells suggests that HSPs may act as a link between infection and autoimmunity (195). Although the controversy remains, the molecular mimicry caused by structural similarity between microbial HSPs and mammalian HSPs may lead to autoimmunity to self HSPs following bacterial infection (196-198). Consistent with this idea, Hsp110 itself can be immunogenic in certain contexts, such as DNA vaccination against Hsp110 that resulted in priming of T cells reactive with Hsp110 on tumor cells in vivo (159). Increased levels of anti-Hsp110 antibodies and enhanced expression of Hsp110 have been observed in mice with experimental autoimmune encephalomyelitis (EAE) as well as patients with MS (199), which support a potential role of Hsp110 in inflammatory autoimmune pathology.

Although therapeutic inhibition of Hsp90 has been evaluated in the context of cancer treatment (200), growing evidence indicates that Hsp90 inhibitors also provide benefits for treatment of inflammatory disorders. Inhibition of Hsp90 using a small molecular inhibitor prevented LPS-induced NF- $\kappa \mathrm{B}$ activation and nitric oxide production, and attenuated the inflammatory response in EAE (201). Inhibition of Hsp90 reduced the activation of the transcription factors STATs and NF- $\kappa$ B by pro-inflammatory cytokines in atherosclerotic mice (202). These results suggest involvement of Hsp90 and potentially other HSPs (e.g., Hsp110, Grp170) in an inflammatory response possibly through modulating key regulators of immune signaling pathways such as JAK/STATs, TLR4, and NF- $\kappa$ B. We recently showed that UPR response enhanced the production of inflammatory cytokines (e.g., IFN- $\beta$ ) by DCs stimulated by poly(I:C), which involved both TLR3 and melanoma differentiation-associated gene-5. This enhanced inflammatory response was associated with increased activation of NF- $\mathrm{KB}$ and IRF3 signaling as well as the splicing of X-box-binding protein-1 (XBP-1), a transcription factor known to regulate ER chaperone genes such as Grp170 (203). It is not clear if the induction of intracellular Grp170 and/ or secretion of Grp170 contribute to UPR-amplified inflammatory response in this context. Moreover, Grp170 is known to bind with immunoglobulin in B cells (51) and was suggested to functionally compensate for Grp94/Gp96 to facilitate the assembly of immunoglobulin (204), implicating a potential role of Grp170 in B cell functions. Strikingly, lupus-like autoimmune disorder and systemic inflammation are induced in Grp94/Gp96 
TABLE 1 | The activity of large heat shock proteins in multiple diseases.

\begin{tabular}{|c|c|c|c|}
\hline & Pathology & Activity & Reference \\
\hline \multirow[t]{7}{*}{ Hsp110 } & Traumatic brain injury & Reduce injury at impact site & (22) \\
\hline & Amyotrophic lateral sclerosis & Prevent the neuron toxicity mediated by mutant SOD1 protein & (90) \\
\hline & Alzheimer's disease & Maintain a proper folding environment for phosphorylation and dephosphorylation of tau and APP processing & (93) \\
\hline & Cancer & Upregulate $\beta$-catenin and transcription of Wnt-targeted genes; suppress cancer cell apoptosis & $(41,97)$ \\
\hline & Inflammatory bowel disease & $\begin{array}{l}\text { Impair CD1d signal induced NKT cell-mediated intestinal inflammation; enhance treatment resistance by } \\
\text { upregulating Bcl-2 and IL-17 }\end{array}$ & $(164,167)$ \\
\hline & Gastric ulcer healing & Delay wound healing by suppressing the expression of stromal cell-derived factor 1 & $(170)$ \\
\hline & Multiple sclerosis & Increased levels of anti-Hsp110 antibodies & $(199)$ \\
\hline \multirow[t]{5}{*}{ Grp170 } & Alzheimer's disease & Maintain neuroprotective functions of sAPP alpha & (92) \\
\hline & Acute lung injury & Protect alveolar cells after LPS exposure & $(107)$ \\
\hline & Obesity and diabetes & Promote insulin release and enhance the insulin Sensitivity; increased autoantibodies to Grp170 & $(171,173-176)$ \\
\hline & Myocardial infarction & Inhibit activation of capase-3 and release of mitochondrial cytochrome C & $(181)$ \\
\hline & Idiopathic pulmonary fibrosis & Protect against bleomycin-induced lung injury; promote lung fibrosis by elevating levels of TGF- $\beta 1$ & (182) \\
\hline
\end{tabular}

transgenic mice, in which Grp94/Gp96 was engineered for cell surface expression (205). Thus, development of pharmacological inhibitors selectively targeting Hsp110 or Grp170 may provide new opportunities to treat certain inflammatory or immunerelated diseases (Table $\mathbf{1}$ ).

\section{CONCLUSION}

Like other chaperone molecules involve in intracellular protein quality control, Hsp110 and Grp170 play essential roles for maintaining and restoring protein homeostasis under physiological and stress conditions. The upregulation of these large HSPs as part of stress response (e.g., heat shock response, UPR) generally provide a cytoprotective effect via assistance with protein refolding. Therefore, their manipulation may be strategically used to slow progress of certain diseases associated with protein misfolding or aggregation (e.g., neurodegeneration) or treat cancers that highly express Hsp110 or Grp170 to maintain oncogenic signaling for sustained proliferation and survivals. Due to their superior capacity to hold and target protein antigens for DC-mediated cross-presentation, these large HSPs have been used to develop antigen-targeted cancer vaccines and to enhance the immunogenicity of cancer cells. The efficient generation of an antitumor immune response by large HSP-based immunotherapy in animal models of several cancers has led to an ongoing phase I clinical trial in patients with advanced melanoma. Despite that these large HSPs are typically considered to be homeostatic factors in maintaining cellular function and tissue integrity, it is not

\section{REFERENCES}

1. Lee AS. Mammalian stress response: induction of the glucose-regulated protein family.CurrOpinCellBiol(1992)4(2):267-73.doi:10.1016/0955-0674(92)90042-B

2. Shiu RP, Pouyssegur J, Pastan I. Glucose depletion accounts for the induction of two transformation-sensitive membrane proteinsin Rous sarcoma virus-transformed chick embryo fibroblasts. Proc Natl Acad Sci U S A (1977) 74(9):3840-4. doi:10.1073/pnas.74.9.3840

3. Pouyssegur J, Shiu RP, Pastan I. Induction of two transformation-sensitive membrane polypeptides in normal fibroblasts by a block in glycoprotein synthesis or glucose deprivation. Cell (1977) 11(4):941-7. doi:10.1016/0092-8674(77)90305-1 surprising that they are involved in certain immunopathologies (e.g., inflammatory or immune-related diseases) given the welldocumented immunoregulatory activities of surface or extracellular HSPs including the large HSPs at the interface of innate and adaptive immunity. A better understanding of multifunctional roles of Hsp110 or Grp170, defined by their expression compartmentalization as well as the nature, magnitude, or duration of stress signals in different contexts, will offer important insight into their pathogenic relevancies and assist in the design of new potential therapies for treatment of inflammatory disorders (e.g., IBD, MS).

\section{AUTHOR CONTRIBUTIONS}

All authors listed, have made substantial, direct, and intellectual contribution to the work, and approved it for publication.

\section{FUNDING}

The present study was supported in part by Natural Science Foundation of China (NSFC) Grants No. 81202329, No. 31370875, Foundation for Distinguished Young Teacher in Higher Education of Guangdong Yq2013034, National Institutes of Health (NIH) Grants CA175033, CA154708, CA099326, Department of Defense (DOD) W81XWH-11-1-0481, and NCI Cancer Center Support Grant to VCU Massey Cancer Center P30CA16059. $\mathrm{X}-\mathrm{YW}$ is the Mary Anderson Harrison Distinguished Professor in Cancer Research.

4. Easton DP, Kaneko Y, Subjeck JR. The hsp110 and Grp1 70 stress proteins: newly recognized relatives of the Hsp70s. Cell Stress Chaperones (2000) 5(4):276-90. doi:10.1379/1466-1268(2000)005<0276:THAGSP > 2.0.CO;2

5. Wang XY, Subjeck JR. High molecular weight stress proteins: identification, cloning and utilisation in cancer immunotherapy. Int J Hyperthermia (2013) 29(5):364-75. doi:10.3109/02656736.2013.803607

6. Gething MJ, Sambrook J. Protein folding in the cell. Nature (1992) 355(6355):33-45. doi:10.1038/355033a0

7. Craig EA, Gambill BD, Nelson RJ. Heat shock proteins: molecular chaperones of protein biogenesis. Microbiol Rev (1993) 57(2):402-14.

8. Hartl FU. Molecular chaperones in cellular protein folding. Nature (1996) 381(6583):571-9. doi:10.1038/381571a0 
9. Wang XY, Facciponte JG, Subjeck JR. Molecular chaperones and cancer immunotherapy. Handb Exp Pharmacol (2006) 172(172):305-29. doi:10.1007/3-540-29717-0_13

10. Wang H, Pezeshki AM, Yu X, Guo C, Subjeck JR, Wang XY. The endoplasmic reticulum chaperone GRP170: from immunobiology to cancer therapeutics. Front Oncol (2014) 4:377. doi:10.3389/fonc.2014.00377

11. Lee-Yoon D, Easton D, Murawski M, Burd R, Subjeck JR. Identification of a major subfamily of large hsp70-like proteins through the cloning of the mammalian 110-kDa heat shock protein. J Biol Chem (1995) 270(26):15725-33. doi:10.1074/jbc.270.26.15725

12. Chen X, Easton D, Oh HJ, Lee-Yoon DS, Liu X, Subjeck J. The $170 \mathrm{kDa}$ glucose regulated stress protein is a large HSP70-, HSP110-like protein of the endoplasmic reticulum. FEBS Lett (1996) 380(1-2):68-72. doi:10.1016/0014-5793(96)00011-7

13. Hylander BL, Chen X, Graf PC, Subjeck JR. The distribution and localization of hsp110 in brain. Brain Res (2000) 869(1-2):49-55. doi:10.1016/ S0006-8993(00)02346-5

14. Yasuda K, Nakai A, Hatayama T, Nagata K. Cloning and expression of murine high molecular mass heat shock proteins, HSP105. J Biol Chem (1995) 270(50):29718-23. doi:10.1074/jbc.270.50.29718

15. Storozhenko S, De Pauw P, Kushnir S, Van Montagu M, Inze D. Identification of an Arabidopsis thaliana cDNA encoding a HSP70-related protein belonging to the HSP110/SSE1 subfamily. FEBS Lett (1996) 390(1):113-8. doi:10.1016/0014-5793(96)00640-0

16. Kojima R, Randall J, Brenner BM, Gullans SR. Osmotic stress protein 94 (Osp94). A new member of the Hsp110/SSE gene subfamily. J Biol Chem (1996) 271(21):12327-32. doi:10.1074/jbc.271.21.12327

17. Kaneko Y, Nishiyama H, Nonoguchi K, Higashitsuji H, Kishishita M, Fujita J. A novel hsp110-related gene, apg-1, that is abundantly expressed in the testis responds to a low temperature heat shock rather than the traditional elevated temperatures. J Biol Chem (1997) 272(5):2640-5. doi:10.1074/ jbc. 272.5 .2640

18. Kaneko Y, Kimura T, Kishishita M, Noda Y, Fujita J. Cloning of apg-2 encoding a novel member of heat shock protein 110 family. Gene (1997) 189(1):19-24. doi:10.1016/S0378-1119(96)00807-4

19. Yagita $Y$, Kitagawa K, Taguchi A, Ohtsuki T, Kuwabara K, Mabuchi T, et al. Molecular cloning of a novel member of the HSP110 family of genes, ischemia-responsive protein $94 \mathrm{kDa}$ (irp94), expressed in rat brain after transient forebrain ischemia. J Neurochem (1999) 72(4):1544-51. doi:10.1046/j.1471-4159.1999.721544.x

20. Saito Y, Yamagishi N, Hatayama T. Nuclear localization mechanism of Hsp105beta and its possible function in mammalian cells. J Biochem (2009) 145(2):185-91. doi:10.1093/jb/mvn155

21. Subjeck JR, Sciandra JJ, Chao CF, Johnson RJ. Heat shock proteins and biological response to hyperthermia. Br J Cancer Suppl (1982) 45(5):127-31.

22. Eroglu B, Kimbler DE, Pang J, Choi J, Moskophidis D, Yanasak N, et al. Therapeutic inducers of the HSP70/HSP110 protect mice against traumatic brain injury. J Neurochem (2014) 130(5):626-41. doi:10.1111/jnc.12781

23. Manto MU. Isolated cerebellar dysarthria associated with a heat stroke. Clin Neurol Neurosurg (1996) 98(1):55-6. doi:10.1016/0303-8467(95)00089-5

24. Albukrek D, Bakon M, Moran DS, Faibel M, Epstein Y. Heat-stroke-induced cerebellar atrophy: clinical course, CT and MRI findings. Neuroradiology (1997) 39(3):195-7. doi:10.1007/s002340050392

25. Lindquist S, Craig EA. The heat-shock proteins. Annu Rev Genet (1988) 22:631-77. doi:10.1146/annurev.ge.22.120188.003215

26. Black AR, Subjeck JR. The biology and physiology of the heat shock and glucose-regulated stress protein systems. Methods Achiev Exp Pathol (1991) 15:126-66.

27. Zhang Y, Huang L, Zhang J, Moskophidis D, Mivechi NF. Targeted disruption of hsf1 leads to lack of thermotolerance and defines tissue-specific regulation for stress-inducible Hsp molecular chaperones. J Cell Biochem (2002) 86(2):376-93. doi:10.1002/jcb.10232

28. Ostberg JR, Kaplan KC, Repasky EA. Induction of stress proteins in a panel of mouse tissues by fever-range whole body hyperthermia. Int J Hyperthermia (2002) 18(6):552-62. doi:10.1080/02656730210166168

29. Chen S, Brown IR. Neuronal expression of constitutive heat shock proteins: implications for neurodegenerative diseases. Cell Stress Chaperones (2007) 12(1):51-8. doi:10.1379/CSC-236R.1
30. Wakatsuki T, Hatayama T. Characteristic expression of $105-\mathrm{kDa}$ heat shock protein (HSP105) in various tissues of nonstressed and heat-stressed rats. Biol Pharm Bull (1998) 21(9):905-10. doi:10.1248/bpb.21.905

31. Ishihara K, Yamagishi N, Hatayama T. Protein kinase CK2 phosphorylates Hsp105 alpha at Ser509 and modulates its function. Biochem J (2003) 371(Pt 3):917-25. doi:10.1042/bj20021331

32. Hatayama T, Yasuda K, Yasuda K. Association of HSP105 with HSC70 in high molecular mass complexes in mouse FM3A cells. Biochem Biophys Res Commun (1998) 248(2):395-401. doi:10.1006/bbrc.1998.8979

33. Ishihara K, Yasuda K, Hatayama T. Phosphorylation of the $105-\mathrm{kDa}$ heat shock proteins, HSP105alpha and HSP105beta, by casein kinase II. Biochem Biophys Res Commun (2000) 270(3):927-31. doi:10.1006/bbrc.2000.2541

34. Brown DD, Christine KS, Showell C, Conlon FL. Small heat shock protein Hsp27 is required for proper heart tube formation. Genesis (2007) 45(11):667-78. doi:10.1002/dvg.20340

35. Kaneko Y, Kimura T, Nishiyama H, Noda Y, Fujita J. Developmentally regulated expression of APG-1, a member of heat shock protein 110 family in murine male germ cells. Biochem Biophys Res Commun (1997) 233(1):113-6. doi:10.1006/bbrc.1997.6410

36. Nonoguchi K, Itoh K, Xue JH, Tokuchi H, Nishiyama H, Kaneko Y, et al. Cloning of human cDNAs for Apg-1 and Apg-2, members of the Hsp110 family, and chromosomal assignment of their genes. Gene (1999) 237(1):21-8. doi:10.1016/S0378-1119(99)00325-X

37. Nonoguchi K, Tokuchi H, Okuno H, Watanabe H, Egawa H, Saito K, et al. Expression of Apg-1, a member of the Hsp110 family, in the human testis and sperm. Int J Urol (2001) 8(6):308-14. doi:10.1046/j.1442-2042.2001.00304.x

38. Yuan JX, Xiao LJ, Lu CL, Zhang XS, Liu T, Chen M, et al. Increased expression of heat shock protein 105 in rat uterus of early pregnancy and its significance in embryo implantation. Reprod Biol Endocrinol (2009) 7:23. doi:10.1186/1477-7827-7-23

39. Zhu Y, Ren C, Wan X, Zhu Y, Zhu J, Zhou H, et al. Gene expression of Hsp70, Hsp90 and Hsp110 families in normal palate and cleft palate during mouse embryogenesis. Toxicol Ind Health (2013) 29(10):915-30. doi: $10.1177 / 0748233712446720$

40. Yan Z, Wei H, Ren C, Yuan S, Fu H, Lv Y, et al. Gene expression of Hsps in normal and abnormal embryonic development of mouse hindlimbs. Hum Exp Toxicol (2015) 34(6):563-74. doi:10.1177/0960327114555927

41. Yu N, Kakunda M, Pham V, Lill JR, Du P, Wongchenko M, et al. HSP105 recruits protein phosphatase $2 \mathrm{~A}$ to dephosphorylate beta-catenin. Mol Cell Biol (2015) 35(8):1390-400. doi:10.1128/MCB.01307-14

42. Sokol SY. Spatial and temporal aspects of Wnt signaling and planar cell polarity during vertebrate embryonic development. Semin Cell Dev Biol (2015) 42:78-85. doi:10.1016/j.semcdb.2015.05.002

43. Sciandra JJ, Subjeck JR. The effects of glucose on protein synthesis and thermosensitivity in Chinese hamster ovary cells. J Biol Chem (1983) 258(20):12091-3.

44. Sciandra JJ, Subjeck JR, Hughes CS. Induction of glucose-regulated proteins during anaerobic exposure and of heat-shock proteins after reoxygenation. Proc Natl Acad Sci U S A (1984) 81(15):4843-7. doi:10.1073/ pnas.81.15.4843

45. Whelan SA, Hightower LE. Differential induction of glucose-regulated and heat shock proteins: effects of $\mathrm{pH}$ and sulfhydryl-reducing agents on chicken embryo cells. J Cell Physiol (1985) 125(2):251-8. doi:10.1002/jcp.1041250212

46. Cai JW, Henderson BW, Shen JW, Subjeck JR. Induction of glucose regulated proteins during growth of a murine tumor. J Cell Physiol (1993) 154(2):22937. doi:10.1002/jcp.1041540204

47. Kuwabara K, Matsumoto M, Ikeda J, Hori O, Ogawa S, Maeda Y, et al. Purification and characterization of a novel stress protein, the $150-\mathrm{kDa}$ oxygen-regulated protein (ORP150), from cultured rat astrocytes and its expression in ischemic mouse brain. J Biol Chem (1996) 271(9):5025-32. doi:10.1074/jbc.271.9.5025

48. Shen J, Hughes C, Chao C, Cai J, Bartels C, Gessner T, et al. Coinduction of glucose-regulated proteins and doxorubicin resistance in Chinese hamster cells. Proc Natl Acad Sci U S A (1987) 84(10):3278-82. doi:10.1073/ pnas.84.10.3278

49. Craven RA, Tyson JR, Colin J, Stirling CJ. A novel subfamily of Hsp70s in the endoplasmic reticulum. Trends Cell Biol (1997) 7(7):277-82. doi:10.1016/ S0962-8924(97)01079-9 
50. Park J, Easton DP, Chen X, MacDonald IJ, Wang XY, Subjeck JR. The chaperoning properties of mouse grp170, a member of the third family of hsp70 related proteins. Biochemistry (2003) 42(50):14893-902. doi:10.1021/ bi030122e

51. Lin HY, Masso-Welch P, Di YP, Cai JW, Shen JW, Subjeck JR. The 170-kDa glucose-regulated stress protein is an endoplasmic reticulum protein that binds immunoglobulin. Mol Biol Cell (1993) 4(11):1109-19. doi:10.1091/ mbc.4.11.1109

52. Giffin L, Yan F, Ben Major M, Damania B. Modulation of Kaposi's sarcoma-associatedherpesvirusinterleukin-6functionbyhypoxia-upregulated protein 1. J Virol (2014) 88(16):9429-41. doi:10.1128/JVI.00511-14

53. Kozutsumi Y, Segal M, Normington K, Gething MJ, Sambrook J. The presence of malfolded proteins in the endoplasmic reticulum signals the induction of glucose-regulated proteins. Nature (1988) 332(6163):462-4. doi:10.1038/332462a0

54. Yoshida H, Haze K, Yanagi H, Yura T, Mori K. Identification of the cis-acting endoplasmic reticulum stress response element responsible for transcriptional induction of mammalian glucose-regulated proteins. Involvement of basic leucine zipper transcription factors. J Biol Chem (1998) 273(50):33741-9. doi:10.1074/jbc.273.50.33741

55. Yoshida H, Okada T, Haze K, Yanagi H, Yura T, Negishi M, et al. Endoplasmic reticulum stress-induced formation of transcription factor complex ERSF including NF-Y (CBF) and activating transcription factors 6alpha and 6beta that activates the mammalian unfolded protein response. Mol Cell Biol (2001) 21(4):1239-48. doi:10.1128/MCB.21.4.1239-1248.2001

56. Nozaki J, Kubota H, Yoshida H, Naitoh M, Goji J, Yoshinaga T, et al. The endoplasmic reticulum stress response is stimulated through the continuous activation of transcription factors ATF6 and XBP1 in Ins2+/Akita pancreatic beta cells. Genes Cells (2004) 9(3):261-70. doi:10.1111/j.1356-9597.2004.00721.x

57. Feldman DE, Chauhan V, Koong AC. The unfolded protein response: a novel component of the hypoxic stress response in tumors. Mol Cancer Res (2005) 3(11):597-605. doi:10.1158/1541-7786.MCR-05-0221

58. Arrington DD, Schnellmann RG. Targeting of the molecular chaperone oxygen-regulated protein 150 (ORP150) to mitochondria and its induction by cellular stress. Am J Physiol Cell Physiol (2008) 294(2):C641-50. doi:10.1152/ ajpcell.00400.2007

59. Johnson JD, Fleshner M. Releasing signals, secretory pathways, and immune function of endogenous extracellular heat shock protein 72. J Leukoc Biol (2006) 79(3):425-34. doi:10.1189/jlb.0905523

60. Hightower LE, Guidon PT Jr. Selective release from cultured mammalian cells of heat-shock (stress) proteins that resemble glia-axon transfer proteins. J Cell Physiol (1989) 138(2):257-66. doi:10.1002/jcp.1041380206

61. Colgan SP, Pitman RS, Nagaishi T, Mizoguchi A, Mizoguchi E, Mayer LF, et al. Intestinal heat shock protein 110 regulates expression of CD1d on intestinal epithelial cells. JClin Invest (2003) 112(5):745-54. doi:10.1172/ JCI200317241

62. Saxena A, Banasavadi-Siddegowda YK, Fan Y, Bhattacharya S, Roy G, Giovannucci DR, et al. Human heat shock protein $105 / 110 \mathrm{kDa}$ (Hsp105/110) regulates biogenesis and quality control of misfolded cystic fibrosis transmembrane conductance regulator at multiple levels. J Biol Chem (2012) 287(23):19158-70. doi:10.1074/jbc.M111.297580

63. Zappasodi R, Bongarzone I, Ghedini GC, Castagnoli L, Cabras AD, Messina A, et al. Serological identification of HSP105 as a novel non-Hodgkin lymphoma therapeutic target. Blood (2011) 118(16):4421-30. doi:10.1182/ blood-2011-06-364570

64. Naaby-Hansen S, Herr JC. Heat shock proteins on the human sperm surface. J Reprod Immunol (2010) 84(1):32-40. doi:10.1016/j.jri.2009.09.006

65. Ozawa K, Tsukamoto Y, Hori O, Kitao Y, Yanagi H, Stern DM, et al. Regulation of tumor angiogenesis by oxygen-regulated protein 150 , an inducible endoplasmic reticulum chaperone. Cancer Res (2001) 61(10):4206-13.

66. Zuo D, Yu X, Guo C, Yi H, Chen X, Conrad DH, et al. Molecular chaperoning by glucose-regulated protein 170 in the extracellular milieu promotes macrophage-mediated pathogen sensing and innate immunity. FASEB $J$ (2012) 26(4):1493-505. doi:10.1096/f.11-197707

67. Hartl FU, Bracher A, Hayer-Hartl M. Molecular chaperones in protein folding and proteostasis. Nature (2011) 475(7356):324-32. doi:10.1038/nature10317
68. Oh HJ, Chen X, Subjeck JR. Hsp110 protects heat-denatured proteins and confers cellular thermoresistance. J Biol Chem (1997) 272(50):31636-40. doi:10.1074/jbc.272.50.31636

69. Wang XY, Chen X, Oh HJ, Repasky E, Kazim L, Subjeck J. Characterization of native interaction of hsp110 with hsp25 and hsc70. FEBS Lett (2000) 465(2-3):98-102. doi:10.1016/S0014-5793(99)01733-0

70. Ishihara K, Yasuda K, Hatayama T. Molecular cloning, expression and localization of human $105 \mathrm{kDa}$ heat shock protein, hsp105. Biochim Biophys Acta (1999) 1444(1):138-42. doi:10.1016/S0167-4781(98)00254-1

71. Melnick J, Dul JL, Argon Y. Sequential interaction of the chaperones BiP and GRP94 with immunoglobulin chains in the endoplasmic reticulum. Nature (1994) 370(6488):373-5. doi:10.1038/370373a0

72. Wang XY, Chen X, Manjili MH, Repasky E, Henderson R, Subjeck JR. Targeted immunotherapy using reconstituted chaperone complexes of heat shock protein 110 and melanoma-associated antigen gp100. Cancer Res (2003) 63(10):2553-60.

73. Wang XY, Arnouk H, Chen X, Kazim L, Repasky EA, Subjeck JR. Extracellular targeting of endoplasmic reticulum chaperone glucose-regulated protein 170 enhances tumor immunity to a poorly immunogenic melanoma. J Immunol (2006) 177(3):1543-51. doi:10.4049/jimmunol.177.3.1543

74. Wang XY, Sun X, Chen X, Facciponte J, Repasky EA, Kane J, et al. Superior antitumor response induced by large stress protein chaperoned protein antigen compared with peptide antigen. J Immunol (2010) 184(11):6309-19. doi:10.4049/jimmunol.0903891

75. Yamagishi N, Yokota M, Yasuda K, Saito Y, Nagata K, Hatayama T. Characterization of stress sensitivity and chaperone activity of Hsp105 in mammalian cells. Biochem Biophys Res Commun (2011) 409(1):90-5. doi:10.1016/j.bbrc.2011.04.114

76. Shorter J. The mammalian disaggregase machinery: Hsp110 synergizes with Hsp70 and Hsp40 to catalyze protein disaggregation and reactivation in a cell-free system. PLoS One (2011) 6(10):e26319. doi:10.1371/journal. pone.0026319

77. Rampelt H, Kirstein-Miles J, Nillegoda NB, Chi K, Scholz SR, Morimoto RI, et al. Metazoan Hsp70 machines use Hsp 110 to power protein disaggregation. EMBO J (2012) 31(21):4221-35. doi:10.1038/emboj.2012.264

78. Raviol H, Sadlish H, Rodriguez F, Mayer MP, Bukau B. Chaperone network in the yeast cytosol: Hsp110 is revealed as an Hsp70 nucleotide exchange factor. EMBO J (2006) 25(11):2510-8. doi:10.1038/sj.emboj.7601139

79. Dragovic Z, Broadley SA, Shomura Y, Bracher A, Hartl FU. Molecular chaperones of the Hsp110 family act as nucleotide exchange factors of Hsp70s. EMBO J (2006) 25(11):2519-28. doi:10.1038/sj.emboj.7601138

80. Andreasson C, Fiaux J, Rampelt H, Druffel-Augustin S, Bukau B. Insights into the structural dynamics of the Hsp110-Hsp70 interaction reveal the mechanism for nucleotide exchange activity. Proc Natl Acad Sci U S A (2008) 105(43):16519-24. doi:10.1073/pnas.0804187105

81. Polier S, Dragovic Z, Hartl FU, Bracher A. Structural basis for the cooperation of Hsp70 and Hsp110 chaperones in protein folding. Cell (2008) 133(6):1068-79. doi:10.1016/j.cell.2008.05.022

82. Weitzmann A, Volkmer J, Zimmermann R. The nucleotide exchange factor activity of Grp170 may explain the non-lethal phenotype of loss of Sill function in man and mouse. FEBS Lett (2006) 580(22):5237-40. doi:10.1016/j. febslet.2006.08.055

83. de Keyzer J, Steel GJ, Hale SJ, Humphries D, Stirling CJ. Nucleotide binding by Lhslp is essential for its nucleotide exchange activity and for function in vivo. J Biol Chem (2009) 284(46):31564-71. doi:10.1074/jbc. M109.055160

84. Andreasson C, Rampelt H, Fiaux J, Druffel-Augustin S, Bukau B. The endoplasmic reticulum Grp170 acts as a nucleotide exchange factor of Hsp70 via a mechanism similar to that of the cytosolic Hsp110. J Biol Chem (2010) 285(16):12445-53. doi:10.1074/jbc.M109.096735

85. Xu X, Sarbeng EB, Vorvis C, Kumar DP, Zhou L, Liu Q. Unique peptide substrate binding properties of $110-\mathrm{kDa}$ heat-shock protein (Hsp110) determine its distinct chaperone activity. J Biol Chem (2012) 287(8):5661-72. doi:10.1074/jbc.M111.275057

86. Lanneau D, Brunet M, Frisan E, Solary E, Fontenay M, Garrido C. Heat shock proteins: essential proteins for apoptosis regulation. J Cell Mol Med (2008) 12(3):743-61. doi:10.1111/j.1582-4934.2008.00273.x 
87. Tamatani M, Matsuyama T, Yamaguchi A, Mitsuda N, Tsukamoto Y, Taniguchi M, et al. ORP150 protects against hypoxia/ischemia-induced neuronal death. Nat Med (2001) 7(3):317-23. doi:10.1038/85463

88. Wang Y, Wu Z, Li D, Wang D, Wang X, Feng X, et al. Involvement of oxygen-regulated protein 150 in AMP-activated protein kinase-mediated alleviation of lipid-induced endoplasmic reticulum stress. J Biol Chem (2011) 286(13):11119-31. doi:10.1074/jbc.M110.203323

89. Smith HL, Li W, Cheetham ME. Molecular chaperones and neuronal proteostasis. Semin Cell Dev Biol (2015) 40:142-52. doi:10.1016/j. semcdb.2015.03.003

90. Song Y, Nagy M, Ni W, Tyagi NK, Fenton WA, Lopez-Giraldez F, et al. Molecular chaperone Hsp110 rescues a vesicle transport defect produced by an ALS-associated mutant SOD1 protein in squid axoplasm. Proc Natl Acad Sci U S A (2013) 110(14):5428-33. doi:10.1073/pnas.1303279110

91. Ring S, Weyer SW, Kilian SB, Waldron E, Pietrzik CU, Filippov MA, et al. The secreted beta-amyloid precursor protein ectodomain APPs alpha is sufficient to rescue the anatomical, behavioral, and electrophysiological abnormalities of APP-deficient mice. JNeurosci (2007) 27(29):7817-26. doi:10.1523/ JNEUROSCI.1026-07.2007

92. Hartl D, Klatt S, Roch M, Konthur Z, Klose J, Willnow TE, et al. Soluble alpha-APP (sAPPalpha) regulates CDK5 expression and activity in neurons. PLoS One (2013) 8(6):e65920. doi:10.1371/journal.pone.0065920

93. Eroglu B, Moskophidis D, Mivechi NF. Loss of Hsp1 10 leads to age-dependent tau hyperphosphorylation and early accumulation of insoluble amyloid beta. Mol Cell Biol (2010) 30(19):4626-43. doi:10.1128/MCB.01493-09

94. Cornford PA, Dodson AR, Parsons KF, Desmond AD, Woolfenden A, Fordham $\mathrm{M}$, et al. Heat shock protein expression independently predicts clinical outcome in prostate cancer. Cancer Res (2000) 60(24):7099-105.

95. van de Vijver MJ, He YD, van’t Veer LJ, Dai H, Hart AA, Voskuil DW, et al. A gene-expression signature as a predictor of survival in breast cancer. $N$ Engl J Med (2002) 347(25):1999-2009. doi:10.1056/NEJMoa021967

96. Kai M, Nakatsura T, Egami H, Senju S, Nishimura Y, Ogawa M. Heat shock protein 105 is overexpressed in a variety of human tumors. Oncol Rep (2003) 10(6):1777-82.

97. Yamagishi N, Ishihara K, Saito Y, Hatayama T. Hsp105 family proteins suppress staurosporine-induced apoptosis by inhibiting the translocation of Bax to mitochondria in HeLa cells. Exp Cell Res (2006) 312(17):3215-23. doi:10.1016/j.yexcr.2006.06.007

98. Hatayama T, Yamagishi N, Minobe E, Sakai K. Role of hsp105 in protection against stress-induced apoptosis in neuronal PC12 cells. Biochem Biophys Res Commun (2001) 288(3):528-34. doi:10.1006/bbrc.2001.5802

99. Hosaka S, Nakatsura T, Tsukamoto H, Hatayama T, Baba H, Nishimura Y. Synthetic small interfering RNA targeting heat shock protein 105 induces apoptosis of various cancer cells both in vitro and in vivo. Cancer Sci (2006) 97(7):623-32. doi:10.1111/j.1349-7006.2006.00217.x

100. Bienz M, Clevers H. Linking colorectal cancer to Wnt signaling. Cell (2000) 103(2):311-20. doi:10.1016/S0092-8674(00)00122-7

101. Polakis P. Wnt signaling and cancer. Genes Dev (2000) 14(15):1837-51.

102. Manjili MH, Park J, Facciponte JG, Subjeck JR. HSP110 induces "danger signals" upon interaction with antigen presenting cells and mouse mammary carcinoma. Immunobiology (2005) 210(5):295-303. doi:10.1016/j. imbio.2005.04.002

103. Manjili MH, Park JE, Facciponte JG, Wang XY, Subjeck JR. Immunoadjuvant chaperone, GRP170, induces 'danger signals' upon interaction with dendritic cells. Immunol Cell Biol (2006) 84(2):203-8. doi:10.1111/j.1440-1711.2006.01418.x

104. Gao P, Sun X, Chen X, Subjeck J, Wang XY. Secretion of stress protein grp 170 promotes immune-mediated inhibition of murine prostate tumor. Cancer Immunol Immunother (2009) 58(8):1319-28. doi:10.1007/s00262-008-0647-6

105. Tsukamoto Y, Kuwabara K, Hirota S, Ikeda J, Stern D, Yanagi H, et al. 150-kD oxygen-regulated protein is expressed in human atherosclerotic plaques and allows mononuclear phagocytes to withstand cellular stress on exposure to hypoxia and modified low density lipoprotein. JClin Invest (1996) 98(8):1930-41. doi:10.1172/JCI118994

106. Ozawa K, Kuwabara K, Tamatani M, Takatsuji K, Tsukamoto Y, Kaneda S, et al. $150-\mathrm{kDa}$ oxygen-regulated protein (ORP150) suppresses hypoxia-induced apoptotic cell death. J Biol Chem (1999) 274(10):6397-404. doi:10.1074/ jbc. 274.10 .6397
107. Nakagomi T, Kitada O, Kuribayashi K, Yoshikawa H, Ozawa K, Ogawa $\mathrm{S}$, et al. The 150-kilodalton oxygen-regulated protein ameliorates lipopolysaccharide-induced acute lung injury in mice. Am J Pathol (2004) 165(4):1279-88. doi:10.1016/S0002-9440(10)63387-1

108. Qian J, Yi H, Guo C, Yu X, Zuo D, Chen X, et al. CD204 suppresses large heat shock protein-facilitated priming of tumor antigen gp100-specific T cells and chaperone vaccine activity against mouse melanoma. J Immunol (2011) 187(6):2905-14. doi:10.4049/jimmunol.1100703

109. Huo W, Ye J, Liu R, Chen J, Li Q. Vaccination with a chaperone complex based on PSCA and GRP170 adjuvant enhances the CTL response and inhibits the tumor growth in mice. Vaccine (2010) 28(38):6333-7. doi:10.1016/j. vaccine.2010.06.093

110. Park JE, Facciponte J, Chen X, MacDonald I, Repasky EA, Manjili MH, et al. Chaperoning function of stress protein grp170, a member of the hsp70 superfamily, is responsible for its immunoadjuvant activity. Cancer Res (2006) 66(2):1161-8. doi:10.1158/0008-5472.CAN-05-2609

111. Wang XY, Yi H, Yu X, Zuo D, Subjeck JR. Enhancing antigen cross-presentation and T-cell priming by complexing protein antigen to recombinant large heat-shock protein. Methods Mol Biol (2011) 787:277-87. doi:10.1007/978-1-61779-295-3_21

112. Manjili MH, Henderson R, Wang XY, Chen X, Li Y, Repasky E, et al. Development of a recombinant HSP110-HER-2/neu vaccine using the chaperoning properties of HSP110. Cancer Res (2002) 62(6):1737-42.

113. Murshid A, Gong J, Calderwood SK. Heat-shock proteins in cancer vaccines: agents of antigen cross-presentation. Expert Rev Vaccines (2008) 7(7):1019-30. doi:10.1586/14760584.7.7.1019

114. Murshid A, Gong J, Calderwood SK. The role of heat shock proteins in antigen cross presentation. Front Immunol (2012) 3:63. doi:10.3389/ fimmu.2012.00063

115. Schuette V, Burgdorf S. The ins-and-outs of endosomal antigens for cross-presentation. Curr Opin Immunol (2014) 26:63-8. doi:10.1016/j. coi.2013.11.001

116. Kutomi G, Tamura Y, Okuya K, Yamamoto T, Hirohashi Y, Kamiguchi K, et al. Targeting to static endosome is required for efficient cross-presentation of endoplasmic reticulum-resident oxygen-regulated protein 150-peptide complexes. J Immunol (2009) 183(9):5861-9. doi:10.4049/jimmunol.0803768

117. Wang H, Yu X, Guo C, Zuo D, Fisher PB, Subjeck JR, et al. Enhanced endoplasmic reticulum entry of tumor antigen is crucial for cross-presentation induced by dendritic cell-targeted vaccination. J Immunol (2013) 191(12):6010-21. doi:10.4049/jimmunol.1302312

118. Burgdorf S, Scholz C, Kautz A, Tampe R, Kurts C. Spatial and mechanistic separation of cross-presentation and endogenous antigen presentation. Nat Immunol (2008) 9(5):558-66. doi:10.1038/ni.1601

119. Cebrian I, Visentin G, Blanchard N, Jouve M, Bobard A, Moita C, et al. Sec22b regulates phagosomal maturation and antigen crosspresentation by dendritic cells. Cell (2011) 147(6):1355-68. doi:10.1016/j.cell.2011.11.021

120. Guermonprez P, Saveanu L, Kleijmeer M, Davoust J, Van Endert P, Amigorena S. ER-phagosome fusion defines an MHC class I cross-presentation compartment in dendritic cells. Nature (2003) 425(6956):397-402. doi:10.1038/ nature01911

121. Delneste Y, Magistrelli G, Gauchat J, Haeuw J, Aubry J, Nakamura K, et al. Involvement of LOX-1 in dendritic cell-mediated antigen cross-presentation. Immunity (2002) 17(3):353-62. doi:10.1016/S1074-7613(02)00388-6

122. Berwin B, Hart JP, Rice S, Gass C, Pizzo SV, Post SR, et al. Scavenger receptor-A mediates gp96/GRP94 and calreticulin internalization by antigen-presenting cells. EMBO J (2003) 22(22):6127-36. doi:10.1093/emboj/cdg572

123. Berwin B, Delneste Y, Lovingood RV, Post SR, Pizzo SV. SREC-I, a type F scavenger receptor, is an endocytic receptor for calreticulin. J Biol Chem (2004) 279(49):51250-7. doi:10.1074/jbc.M406202200

124. Theriault JR, Adachi H, Calderwood SK. Role of scavenger receptors in the binding and internalization of heat shock protein 70. J Immunol (2006) 177(12):8604-11. doi:10.4049/jimmunol.177.12.8604

125. Gong J, Zhu B, Murshid A, Adachi H, Song B, Lee A, et al. T cell activation by heat shock protein 70 vaccine requires TLR signaling and scavenger receptor expressed by endothelial cells-1. J Immunol (2009) 183(5):3092-8. doi:10.4049/jimmunol.0901235

126. Murshid A, Gong J, Calderwood SK. Heat shock protein 90 mediates efficient antigen cross presentation through the scavenger receptor expressed 
by endothelial cells-I. J Immunol (2010) 185(5):2903-17. doi:10.4049/ jimmunol.0903635

127. Facciponte JG, Wang XY, Subjeck JR. Hsp110 and Grp170, members of the Hsp70 superfamily, bind to scavenger receptor-A and scavenger receptor expressed by endothelial cells-I. Eur JImmunol (2007) 37(8):2268-79. doi:10.1002/eji.200737127

128. Wang XY, Facciponte J, Chen X, Subjeck JR, Repasky EA. Scavenger receptor-A negatively regulates antitumor immunity. Cancer Res (2007) 67(10):4996-5002. doi:10.1158/0008-5472.CAN-06-3138

129. Yu X, Guo C, Fisher PB, Subjeck JR, Wang XY. Scavenger receptors: emerging roles in cancer biology and immunology. Adv Cancer Res (2015) 128:309-64. doi:10.1016/bs.acr.2015.04.004

130. Srivastava PK, DeLeo AB, Old LJ. Tumor rejection antigens of chemically induced sarcomas of inbred mice. Proc Natl Acad Sci U S A (1986) 83(10):3407-11. doi:10.1073/pnas.83.10.3407

131. Ullrich SJ, Robinson EA, Law LW, Willingham M, Appella E. A mouse tumor-specific transplantation antigen is a heat shock-related protein. Proc Natl Acad Sci U S A (1986) 83(10):3121-5. doi:10.1073/pnas.83.10.3121

132. Udono H, Srivastava PK. Heat shock protein 70 -associated peptides elicit specific cancer immunity. J Exp Med (1993) 178(4):1391-6. doi:10.1084/ jem.178.4.1391

133. Arnold D, Faath S, Rammensee H, Schild H. Cross-priming of minor histocompatibility antigen-specific cytotoxic $\mathrm{T}$ cells upon immunization with the heat shock protein gp96. J Exp Med (1995) 182(3):885-9. doi:10.1084/ jem.182.3.885

134. Nieland TJ, Tan MC, Monne-van Muijen M, Koning F, Kruisbeek AM, van Bleek GM. Isolation of an immunodominant viral peptide that is endogenously bound to the stress protein GP96/GRP94. Proc Natl Acad Sci U S A (1996) 93(12):6135-9. doi:10.1073/pnas.93.12.6135

135. Ishii $\mathrm{T}$, Udono $\mathrm{H}$, Yamano $\mathrm{T}$, Ohta $\mathrm{H}$, Uenaka $\mathrm{A}$, Ono $\mathrm{T}$, et al. Isolation of MHC class I-restricted tumor antigen peptide and its precursors associated with heat shock proteins hsp70, hsp90, and gp96. J Immunol (1999) 162(3):1303-9.

136. Castelli C, Ciupitu AM, Rini F, Rivoltini L, Mazzocchi A, Kiessling R, et al. Human heat shock protein 70 peptide complexes specifically activate antimelanoma T cells. Cancer Res (2001) 61(1):222-7.

137. Rivoltini L, Castelli C, Carrabba M, Mazzaferro V, Pilla L, Huber V, et al. Human tumor-derived heat shock protein 96 mediates in vitro activation and in vivo expansion of melanoma- and colon carcinoma-specific $\mathrm{T}$ cells. J Immunol (2003) 171(7):3467-74. doi:10.4049/jimmunol.171.7.3467

138. Srivastava P. Interaction of heat shock proteins with peptides and antigen presenting cells: chaperoning of the innate and adaptive immune responses. Annu Rev Immunol (2002) 20:395-425. doi:10.1146/annurev. immunol.20.100301.064801

139. Wang XY, Kazim L, Repasky EA, Subjeck JR. Characterization of heat shock protein 110 and glucose-regulated protein 170 as cancer vaccines and the effect of fever-range hyperthermia on vaccine activity. JImmunol (2001) 166(1):490-7. doi:10.4049/jimmunol.166.1.490

140. Moroi Y, Mayhew M, Trcka J, Hoe MH, Takechi Y, Hartl FU, et al. Induction of cellular immunity by immunization with novel hybrid peptides complexed to heat shock protein 70. Proc Natl Acad Sci U S A (2000) 97(7):3485-90. doi:10.1073/pnas.97.7.3485

141. MacAry PA, Javid B, Floto RA, Smith KG, Oehlmann W, Singh M, et al. HSP70 peptide binding mutants separate antigen delivery from dendritic cell stimulation. Immunity (2004) 20(1):95-106. doi:10.1016/ S1074-7613(03)00357-1

142. Tobian AA, Canaday DH, Harding CV. Bacterial heat shock proteins enhance class II MHC antigen processing and presentation of chaperoned peptides to CD4+ T cells. J Immunol (2004) 173(8):5130-7. doi:10.4049/ jimmunol.173.8.5130

143. Wang XY, Kazim L, Repasky EA, Subjeck JR. Immunization with tumor-derived ER chaperone grp170 elicits tumor-specific CD8+ T-cell responses and reduces pulmonary metastatic disease. Int J Cancer (2003) 105(2):226-31. doi:10.1002/ijc.11058

144. Belli F, Testori A, Rivoltini L, Maio M, Andreola G, Sertoli MR, et al. Vaccination of metastatic melanoma patients with autologous tumor-derived heat shock protein gp96-peptide complexes: clinical and immunologic findings. J Clin Oncol (2002) 20(20):4169-80. doi:10.1200/JCO.2002.09.134
145. Manjili MH, Wang XY, Chen X, Martin T, Repasky EA, Henderson R, et al. HSP110-HER2/neu chaperone complex vaccine induces protective immunity against spontaneous mammary tumors in HER-2/neu transgenic mice. J Immunol (2003) 171(8):4054-61. doi:10.4049/jimmunol.171.8.4054

146. Kim H, Sun X, Subjeck J, Wang X-Y. Evaluation of renal cell carcinoma vaccines targeting carbonic anhydrase IX using heat shock protein 110. Cancer Immunol Immunother (2007) 56(7):1097-105. doi:10.1007/ s00262-006-0258-z

147. Wang Y, Wang XY, Subjeck JR, Shrikant PA, Kim HL. Temsirolimus, an mTOR inhibitor, enhances anti-tumour effects of heat shock protein cancer vaccines. Br J Cancer (2011) 104(4):643-52. doi:10.1038/bjc.2011.15

148. Yuan B, Xian R, Wu X, Jing J, Chen K, Liu G, et al. Endoplasmic reticulum chaperone glucose regulated protein 170-Pokemon complexes elicit a robust antitumor immune response in vivo. Immunobiology (2012) 217(7):738-42. doi:10.1016/j.imbio.2012.01.006

149. McLaughlin K, Carr VB, Iqbal M, Seago J, Lefevre EA, Robinson L, et al. Hsp110-mediated enhancement of CD4+ T cell responses to the envelope glycoprotein of members of the family Flaviviridae in vitro does not occur in vivo. Clin Vaccine Immunol (2011) 18(2):311-7. doi:10.1128/ CVI.00414-10

150. Wang XY, Li Y, Manjili MH, Repasky EA, Pardoll DM, Subjeck JR. Hsp110 over-expression increases the immunogenicity of the murine CT26 colon tumor. Cancer Immunol Immunother (2002) 51(6):311-9. doi:10.1007/ s00262-002-0287-1

151. Arnouk H, Zynda ER, Wang XY, Hylander BL, Manjili MH, Repasky EA, et al. Tumour secreted grp170 chaperones full-length protein substrates and induces an adaptive anti-tumour immune response in vivo. Int $J$ Hyperthermia (2010) 26(4):366-75. doi:10.3109/02656730903485910

152. Gao P, Sun X, Chen X, Wang Y, Foster BA, Subjeck J, et al. Secretable chaperone Grp170 enhances therapeutic activity of a novel tumor suppressor, mda-7/IL-24. Cancer Res (2008) 68(10):3890-8. doi:10.1158/0008-5472. CAN-08-0156

153. Fisher PB, Gopalkrishnan RV, Chada S, Ramesh R, Grimm EA, Rosenfeld MR, et al. mda-7/IL-24, a novel cancer selective apoptosis inducing cytokine gene: from the laboratory into the clinic. Cancer Biol Ther (2003) 2(4 Suppl 1):S23-37. doi:10.4161/cbt.458

154. Akira S, Takeda K. Toll-like receptor signalling. Nat Rev Immunol (2004) 4(7):499-511. doi:10.1038/nri1391

155. Yu X, Guo C, Yi H, Qian J, Fisher PB, Subjeck JR, et al. A multifunctional chimeric chaperone serves as a novel immune modulator inducing therapeutic antitumor immunity. Cancer Res (2013) 73(7):2093-103. doi:10.1158/00085472.CAN-12-1740

156. Chen S, Ou R, Tang J, Deng X, Wu Y, van Velkinburgh JC, et al. Enhanced anti-tumor effects of HPV16E7(49-57)-based vaccine by combined immunization with poly(I:C) and oxygen-regulated protein 150. Cancer Epidemiol (2013) 37(2):172-8. doi:10.1016/j.canep.2012.10.005

157. Calderwood SK, Khaleque MA, Sawyer DB, Ciocca DR. Heat shock proteins in cancer: chaperones of tumorigenesis. Trends Biochem Sci (2006) 31(3):164-72. doi:10.1016/j.tibs.2006.01.006

158. Kretowski R, Stypulkowska A, Cechowska-Pasko M. Low-glucose medium induces ORP150 expression and exerts inhibitory effect on apoptosis and senescence of human breast MCF7 cells. Acta Biochim Pol (2013) 60(2):167-73.

159. Miyazaki M, Nakatsura T, Yokomine K, Senju S, Monji M, Hosaka S, et al. DNA vaccination of HSP105 leads to tumor rejection of colorectal cancer and melanoma in mice through activation of both CD4 T cells and CD8 T cells. Cancer Sci (2005) 96(10):695-705. doi:10.1111/j.1349-7006.2005.00093.x

160. El-Gabalawy H, Guenther LC, Bernstein CN. Epidemiology of immune-mediated inflammatory diseases: incidence, prevalence, natural history, and comorbidities. J Rheumatol Suppl (2010) 85:2-10. doi:10.3899/ jrheum.091461

161. Beyaert R, Beaugerie L, Van Assche G, Brochez L, Renauld JC, Viguier M, et al. Cancer risk in immune-mediated inflammatory diseases (IMID). Mol Cancer (2013) 12(1):98. doi:10.1186/1476-4598-12-98

162. Van Eden W, Wick G, Albani S, Cohen I. Stress, heat shock proteins, and autoimmunity: how immune responses to heat shock proteins are to be used for the control of chronic inflammatory diseases. Ann N Y Acad Sci (2007) 1113:217-37. doi:10.1196/annals.1391.020 
163. Mansilla MJ, Montalban X, Espejo C. Heat shock protein 70: roles in multiple sclerosis. Mol Med (2012) 18:1018-28. doi:10.2119/molmed.2012.00119

164. Adachi T, Sakurai T, Kashida H, Mine H, Hagiwara S, Matsui S, et al. Involvement of heat shock protein a4/apg-2 in refractory inflammatory bowel disease. Inflamm Bowel Dis (2015) 21(1):31-9. doi:10.1097/ MIB.0000000000000244

165. Kondo T, Koga S, Matsuyama R, Miyagawa K, Goto R, Kai H, et al. Heat shock response regulates insulin sensitivity and glucose homeostasis: pathophysiological impact and therapeutic potential. Curr Diabetes Rev (2011) 7(4):264-9. doi:10.2174/157339911796397811

166. Rajaiah R, Moudgil KD. Heat-shock proteins can promote as well as regulate autoimmunity. Autoimmun Rev (2009) 8(5):388-93. doi:10.1016/j. autrev.2008.12.004

167. Olszak T, Neves JF, Dowds CM, Baker K, Glickman J, Davidson NO, et al. Protective mucosal immunity mediated by epithelial CD1d and IL-10. Nature (2014) 509(7501):497-502. doi:10.1038/nature 13150

168. Li C, Liu D, Yuan Y, Huang S, Shi M, Tao K, et al. Overexpression of Apg-2 increases cell proliferation and protects from oxidative damage in BaF3BCR/ABL cells. Int J Oncol (2010) 36(4):899-904.

169. Crawford KC, Vega Flores M, Oehlers SH, Hall CJ, Crosier KE, Crosier PS. Zebrafish heat shock protein a4 genes in the intestinal epithelium are up-regulated during inflammation. Genesis (2011) 49(12):905-11. doi:10.1002/dvg. 20767

170. Sakurai T, Kashida H, Hagiwara S, Nishida N, Watanabe T, Fujita J, et al. Heat shock protein A4 controls cell migration and gastric ulcer healing. Dig Dis Sci (2015) 60(4):850-7. doi:10.1007/s10620-015-3561-8

171. Kobayashi T, Yura T, Yanagi H. The increment of anti-ORP150 autoantibody in initial stages of atheroma in high-fat diet fed mice. J Vet Med Sci (2002) 64(2):177-80. doi:10.1292/jvms.64.177

172. Kobayashi T, Ogawa S, Yura T, Yanagi H. Abundant expression of $150-\mathrm{kDa}$ oxygen-regulated protein in mouse pancreatic beta cells is correlated with insulin secretion. Biochem Biophys Res Commun (2000) 267(3):831-7. doi:10.1006/bbrc.1999.2052

173. Kobayashi T, Ohta Y. $150-\mathrm{kD}$ oxygen-regulated protein is an essential factor for insulin release. Pancreas (2005) 30(4):299-306. doi:10.1097/01. mpa.0000163020.63478.fe

174. Nakatani Y, Kaneto H, Kawamori D, Yoshiuchi K, Hatazaki M, Matsuoka $\mathrm{TA}$, et al. Involvement of endoplasmic reticulum stress in insulin resistance and diabetes. J Biol Chem (2005) 280(1):847-51. doi:10.1074/jbc. M411860200

175. Ozawa K, Miyazaki M, Matsuhisa M, Takano K, Nakatani Y, Hatazaki $\mathrm{M}$, et al. The endoplasmic reticulum chaperone improves insulin resistance in type 2 diabetes. Diabetes (2005) 54(3):657-63. doi:10.2337/ diabetes.54.3.657

176. Nakatani Y, Kaneto H, Hatazaki M, Yoshiuchi K, Kawamori D, Sakamoto K, et al. Increased stress protein ORP150 autoantibody production in Type 1 diabetic patients. Diabet Med (2006) 23(2):216-9. doi:10.1111/j.1464-5491.2005.01766.x

177. Deng WH, Chen C, Wang WX, Yu J, Li JY, Liu L. Effects of ORP150 on appearance and function of pancreatic beta cells following acute necrotizing pancreatitis. Pathol Res Pract (2011) 207(6):370-6. doi:10.1016/j. prp.2011.03.006

178. Dekki N, Refai E, Holmberg R, Kohler M, Jornvall H, Berggren PO, et al. Transthyretin binds to glucose-regulated proteins and is subjected to endocytosis by the pancreatic beta-cell. Cell Mol Life Sci (2012) 69(10):1733-43. doi:10.1007/s00018-011-0899-8

179. Refai E, Dekki N, Yang SN, Imreh G, Cabrera O, Yu L, et al. Transthyretin constitutes a functional component in pancreatic beta-cell stimulus-secretion coupling. Proc Natl Acad Sci U S A (2005) 102(47):17020-5. doi:10.1073/ pnas.0503219102

180. Sanson M, Ingueneau C, Vindis C, Thiers JC, Glock Y, Rousseau H, et al. Oxygen-regulated protein-150 prevents calcium homeostasis deregulation and apoptosis induced by oxidized LDL in vascular cells. Cell Death Differ (2008) 15(8):1255-65. doi:10.1038/cdd.2008.36

181. Aleshin AN, Sawa Y, Kitagawa-Sakakida S, Bando Y, Ono M, Memon $\mathrm{IA}$, et al. $150-\mathrm{kDa}$ oxygen-regulated protein attenuates myocardial ischemia-reperfusion injury in rat heart. J Mol Cell Cardiol (2005) 38(3):51725. doi:10.1016/j.yjmcc.2005.01.001
182. Tanaka K, Shirai A, Ito Y, Namba T, Tahara K, Yamakawa N, et al. Expression of 150-kDa oxygen-regulated protein (ORP150) stimulates bleomycin-induced pulmonary fibrosis and dysfunction in mice. Biochem Biophys Res Commun (2012) 425(4):818-24. doi:10.1016/j.bbrc.2012.07.158

183. Ng LL, O’Brien RJ, Quinn PA, Squire IB, Davies JE. Oxygen-regulated protein 150 and prognosis following myocardial infarction. Clin Sci (2007) 112(9):477-84. doi:10.1042/CS20060304

184. Saxena A, Russo I, Frangogiannis NG. Inflammation as a therapeutic target in myocardial infarction: learning from past failures to meet future challenges. Transl Res (2016) 167(1):152-66. doi:10.1016/j.trsl.2015.07.002

185. Frangogiannis NG. The inflammatory response in myocardial injury, repair, and remodelling. Nat Rev Cardiol (2014) 11(5):255-65. doi:10.1038/ nrcardio.2014.28

186. Mezzaroma E, Toldo S, Farkas D, Seropian IM, Van Tassell BW, Salloum FN, et al. The inflammasome promotes adverse cardiac remodeling following acute myocardial infarction in the mouse. Proc Natl Acad Sci U S A (2011) 108(49):19725-30. doi:10.1073/pnas.1108586108

187. Mayor A, Martinon F, De Smedt T, Petrilli V, Tschopp J. A crucial function of SGT1 and HSP90 in inflammasome activity links mammalian and plant innate immune responses. Nat Immunol (2007) 8(5):497-503. doi:10.1038/ni1459

188. Cavassani KA, Ishii M, Wen H, Schaller MA, Lincoln PM, Lukacs NW, et al. TLR3 is an endogenous sensor of tissue necrosis during acute inflammatory events. J Exp Med (2008) 205(11):2609-21. doi:10.1084/jem.20081370

189. Tian J, Avalos AM, Mao SY, Chen B, Senthil K, Wu H, et al. Toll-like receptor 9-dependent activation by DNA-containing immune complexes is mediated by HMGB1 and RAGE. Nat Immunol (2007) 8(5):487-96. doi:10.1038/ni1457

190. Imaeda AB, Watanabe A, Sohail MA, Mahmood S, Mohamadnejad M, Sutterwala FS, et al. Acetaminophen-induced hepatotoxicity in mice is dependent on Tlr9 and the Nalp3 inflammasome. JClin Invest (2009) 119(2):305-14. doi:10.1172/JCI35958

191. Matzinger P. Tolerance, danger, and the extended family. Annu Rev Immunol (1994) 12:991-1045. doi:10.1146/annurev.iy.12.040194.005015

192. Matzinger P. The danger model: a renewed sense of self. Science (2002) 296(5566):301-5. doi:10.1126/science.1071059

193. Bianchi ME. DAMPs, PAMPs and alarmins: all we need to know about danger. J Leukoc Biol (2007) 81(1):1-5. doi:10.1189/jlb.0306164

194. Koller B, Bals R, Roos D, Korting HC, Griese M, Hartl D. Innate immune receptors on neutrophils and their role in chronic lung disease. Eur J Clin Invest (2009) 39(7):535-47. doi:10.1111/j.1365-2362.2009.02145.x

195. Zugel U, Schoel B, Yamamoto S, Hengel H, Morein B, Kaufmann SH. Crossrecognition by $\mathrm{CD} 8 \mathrm{~T}$ cell receptor alpha beta cytotoxic $\mathrm{T}$ lymphocytes of peptides in the self and the mycobacterial hsp60 which share intermediate sequence homology. Eur J Immunol (1995) 25(2):451-8. doi:10.1002/ eji.1830250222

196. Salvetti M, Buttinelli C, Ristori G, Carbonari M, Cherchi M, Fiorelli M, et al. T-lymphocyte reactivity to the recombinant mycobacterial $65-$ and $70-\mathrm{kDa}$ heat shock proteins in multiple sclerosis. J Autoimmun (1992) 5(6):691-702. doi:10.1016/0896-8411(92)90186-T

197. Cappello F, Conway de Macario E, Di Felice V, Zummo G, Macario AJ. Chlamydia trachomatis infection and anti-Hsp60 immunity: the two sides of the coin. PLoS Pathog (2009) 5(8):e1000552. doi:10.1371/journal. ppat. 1000552

198. Chodisetti SB, Rai PK, Gowthaman U, Pahari S, Agrewala JN. Potential T cell epitopes of Mycobacterium tuberculosis that can instigate molecular mimicry against host: implications in autoimmune pathogenesis. BMC Immunol (2012) 13:13. doi:10.1186/1471-2172-13-13

199. Minohara M. [Heat shock protein 105 in multiple sclerosis]. Nippon Rinsho (2003) 61(8):1317-22.

200. Whitesell L, Lindquist SL. HSP90 and the chaperoning of cancer. Nat Rev Cancer (2005) 5(10):761-72. doi:10.1038/nrc1716

201. Rice JW, Veal JM, Fadden RP, Barabasz AF, Partridge JM, Barta TE, et al. Small molecule inhibitors of Hsp90 potently affect inflammatory disease pathways and exhibit activity in models of rheumatoid arthritis. Arthritis Rheum (2008) 58(12):3765-75. doi:10.1002/art.24047

202. Madrigal-Matute J, Lopez-Franco O, Blanco-Colio LM, Munoz-Garcia B, Ramos-Mozo P, Ortega L, et al. Heat shock protein 90 inhibitors attenuate inflammatory responses in atherosclerosis. Cardiovasc Res (2010) 86(2):330-7. doi:10.1093/cvr/cvq046 
203. Hu F, Yu X, Wang H, Zuo D, Guo C, Yi H, et al. ER stress and its regulator $\mathrm{X}$-box-binding protein-1 enhance polyIC-induced innate immune response in dendritic cells. EurJ Immunol (2011) 41(4):1086-97. doi:10.1002/eji.201040831

204. Liu B, Li Z. Endoplasmic reticulum HSP90b1 (gp96, grp94) optimizes B-cell function via chaperoning integrin and TLR but not immunoglobulin. Blood (2008) 112(4):1223-30. doi:10.1182/blood-2008-03-143107

205. Liu B, Dai J, Zheng H, Stoilova D, Sun S, Li Z. Cell surface expression of an endoplasmic reticulum resident heat shock protein gp96 triggers MyD88dependent systemic autoimmune diseases. Proc Natl Acad Sci U S A (2003) 100(26):15824-9. doi:10.1073/pnas.2635458100
Conflict of Interest Statement: The authors declare that the research was conducted in the absence of any commercial or financial relationships that could be construed as a potential conflict of interest.

Copyright $\odot 2016$ Zuo, Subjeck and Wang. This is an open-access article distributed under the terms of the Creative Commons Attribution License (CC BY). The use, distribution or reproduction in other forums is permitted, provided the original author(s) or licensor are credited and that the original publication in this journal is cited, in accordance with accepted academic practice. No use, distribution or reproduction is permitted which does not comply with these terms. 